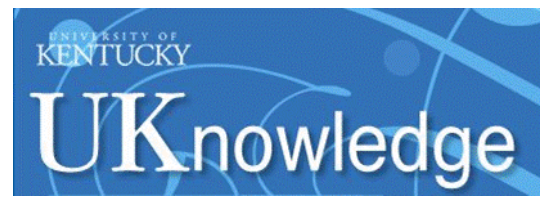

University of Kentucky

UKnowledge

$1-2014$

\title{
Double-Electrode Arc Welding Process: Principle, Variants, Control and Developments
}

\author{
Yi Lu \\ University of Kentucky \\ ShuJun Chen \\ University of Technology, China \\ Yu Shi \\ Lanzhou University of Technology, China \\ Xiangrong Li \\ Adaptive Intelligent Systems LLC \\ Jinsong Chen \\ Adaptive Intelligent Systems LLC
}

See next page for additional authors

Follow this and additional works at: https://uknowledge.uky.edu/ece_facpub

Part of the Electrical and Computer Engineering Commons

Right click to open a feedback form in a new tab to let us know how this document benefits you.

\section{Repository Citation}

Lu, Yi; Chen, ShuJun; Shi, Yu; Li, Xiangrong; Chen, Jinsong; Kvidahl, Lee; and Zhang, Yu Ming, "DoubleElectrode Arc Welding Process: Principle, Variants, Control and Developments" (2014). Electrical and Computer Engineering Faculty Publications. 2.

https://uknowledge.uky.edu/ece_facpub/2

This Article is brought to you for free and open access by the Electrical and Computer Engineering at UKnowledge. It has been accepted for inclusion in Electrical and Computer Engineering Faculty Publications by an authorized administrator of UKnowledge. For more information, please contact UKnowledge@lsv.uky.edu. 


\title{
Double-Electrode Arc Welding Process: Principle, Variants, Control and Developments
}

\author{
Digital Object Identifier (DOI) \\ http://dx.doi.org/10.1016/j.jmapro.2013.08.003 \\ Notes/Citation Information \\ Published in Journal of Manufacturing Processes, v. 16, issue 1, p. 93-108.
}

Per the publisher Elsevier: "NOTICE: this is the author's version of a work that was accepted for publication in Journal of Manufacturing Processes. Changes resulting from the publishing process, such as peer review, editing, corrections, structural formatting, and other quality control mechanisms may not be reflected in this document. Changes may have been made to this work since it was submitted for publication. A definitive version was subsequently published in Journal of Manufacturing Processes, v. 16, issue 1, (January 2014). DOI: http://dx.doi.org/10.1016/j.jmapro.2013.08.003"

\section{Authors}

Yi Lu, ShuJun Chen, Yu Shi, Xiangrong Li, Jinsong Chen, Lee Kvidahl, and Yu Ming Zhang 


\title{
Double-Electrode Arc Welding Process: Principle, Variants, Control and Developments
}

\author{
Yi Lu ${ }^{1,2)}$, ShuJun Chen ${ }^{3)}$, Yu Shi ${ }^{4)}$, Xiangrong $\mathrm{Li}^{1)}$, Jinsong \\ Chen ${ }^{1)}$, Lee Kvidah( ${ }^{5)}$, and YuMing Zhang ${ }^{1,2)}$
}

1. Adaptive Intelligent Systems LLC, 1500 Bull Lea Rd, Lexington, KY 40511 USA

2. University of Kentucky, Department of Electrical and Computer Engineering and Institute for Sustainable Manufacturing, College of Engineering, Lexington, KY 40506 USA

3. Welding Research Institute, Beijing University of Technology, Beijing, China

4. Department of Welding Engineering, Lanzhou University of Technology, Lanzhou, China

5. Huntington Ingalls Industries, Pascagoula, MS 39568, USA

\section{Corresponding Author Email:}

ymzhang@aiswelding.com; yuming.zhang@uky.edu

\begin{abstract}
Double-electrode gas metal arc welding (DE-GMAW) is a novel welding process in which a second electrode, non-consumable or consumable, is added to bypass part of the wire current. The bypass current reduces the heat input in non-consumable DEGMAW or increases the deposition speed in consumable DE-GMAW. The fixed correlation of the heat input with the deposition in conventional GMAW and its variants is thus changed and becomes controllable. At the University of Kentucky, DE-GMAW has been tested/developed by adding a plasma arc welding torch, a GTAW (gas tungsten arc welding) torch, a pair of GTAW torches, and a GMAW torch. Steels and aluminum alloys are welded and the system is powered by one or multiple power supplies with appropriate control methods. The metal transfer has been studied at the University of Kentucky and Shandong University resulting in the desirable spray transfer be obtained with less than 100 A base current for $1.2 \mathrm{~mm}$ diameter steel wire. At Lanzhou University of Technology, pulsed DE-GMAW has been successfully developed to weld aluminum sheets. At the Adaptive Intelligent Systems LLC, DE-GMAW principle has been applied to the submerged arc welding (SAW) and the embedded control systems needed for industrial applications have been developed. The DE-SAW resulted in 1/3 reduction in heat input for a shipbuilding application and the weld penetration depth was successfully feedback controlled. In addition, the bypass concept is extended to the GTAW resulting in the arcingwire GTAW which adds a second arc established between the tungsten and filler to the
\end{abstract}


existing gas tungsten arc. The DE-GMAW is extended to double-electrode arc welding (DE-AW) where the main electrode may not necessarily to be consumable. Recently, the Beijing University of Technology systematically studied the metal transfer in the arcingwire GTAW and found that the desired metal transfer modes may always be obtained from the given wire feed speed by adjusting the wire current and wire position/orientation appropriately. A variety of DE-AW processes are thus available to suit for different applications, using existing arc welding equipment.

Keywords: Double-Electrode (DE), Heat Input, Distortion, Deposition, Gas Metal Arc Welding (GMAW), Gas Tungsten Arc Welding (GTAW), Submerged Arc Welding (SAW), Metal Transfer

\section{Introduction}

Two technologies have been developed to modify GMAW for faster deposition: Tandem GMAW [1, 2] and Variable-Polarity GMAW (VP-GMAW) [3-7]. In Tandem GMAW, two torches have been integrated into one bigger torch, and two close arcs are independently established between their own wire and work-piece in parallel and are adjusted by their own GMAW power supply. In essence, Tandem GMAW is still considered two parallel conventional GMAW processes. It allows the deposition speed be doubled without increasing the arc pressure. For VP-GMAW, liquid droplets are still detached during the reverse polarity (wire positive) period, but the welding wire can be melted faster during the straight polarity (wire negative) period [3, 8]. It was found that to melt the welding wire at the same rate, the base metal heat input could be "up to 47 percent less" than the conventional pulsed GMAW [8]. Thus, when the allowed base metal heat input is given, VP-GMAW may also double the deposition speed. Modifications by adding a laser to form hybrid laser-arc processes [9-16] can penetrate deeper to reduce the needed deposition. However, the resultant process is no longer a pure arc welding process and many advantages associated with arc welding may be compromised.

The double-electrode GMAW [17, 18] and its variants are introduced to increase the deposition speed without increasing the heat input, reduce the heat input without compromising the deposition speed, or freely provide the needed heat input and deposition speed as desired by different applications which typically use GMAW or its variants. For conventional GMAW and its variants, the base metal current is exactly the same as the wire current, i.e., the current flows through the wire. This is the fundamental principle not only for GMAW but also for all other conventional arc welding processes in which an arc must be established between an electrode and the work-piece. Because of this fundamental principle, while the wire current needs to be increased to increase the deposition speed, the 
base metal current increases exactly the same regardless of the actual need of the workpiece. The DE-GMAW changes this principle by introducing a bypass channel such that the deposition speed no longer needs to be proportional to the heat input applied into the work-piece.

In this tutorial, the principle, developments and extension of the DE-GMAW are discussed and outlined to help further develop/extend this process for manufacturing applications.

\section{Double-Electrode GMAW Principle}

Figure 1 demonstrates the principle of the DE-GMAW process and its variants where the main electrode is a consumable wire. The main power supply, main torch/electrode and work-piece form the conventional GMAW process and the main loop. The bypass torch added provides an additional electrode to form an additional arc, i.e., the bypass arc, with the main electrode and closes the bypass loop. In Figure 1, the bypass arc is powered by an added second power supply but it may also be powered by the same main power supply as will be mentioned later in the paper.

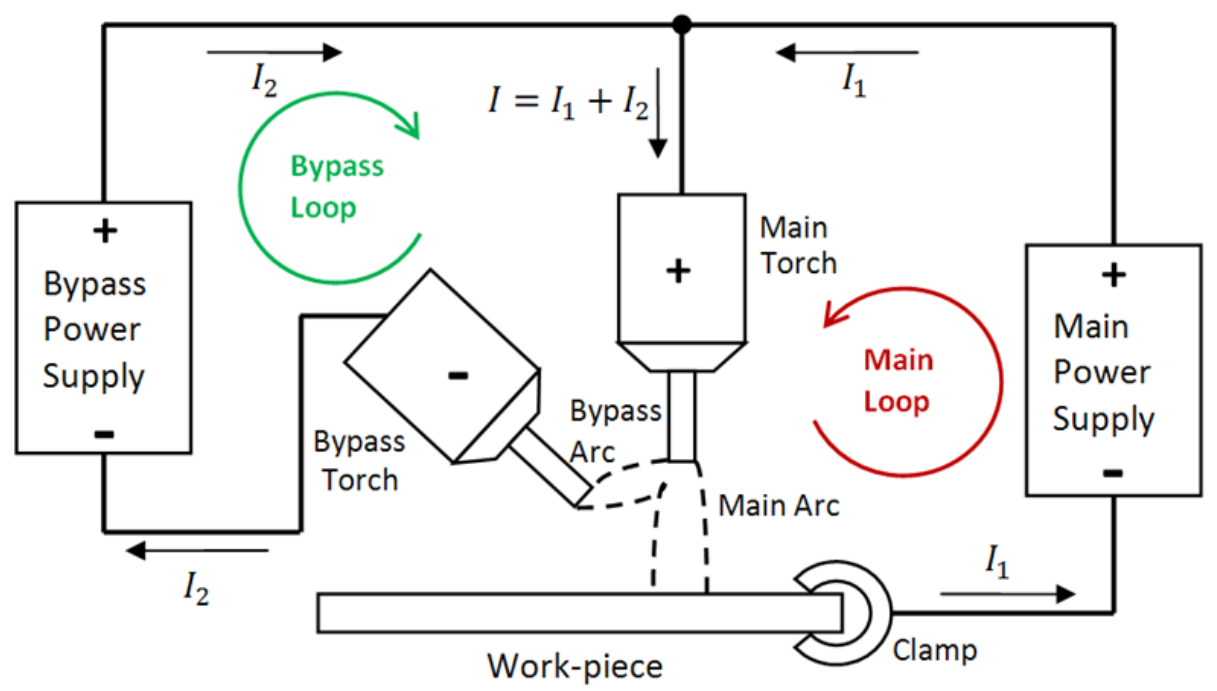

Figure 1 Current relationship in DE-GMAW process. The wire current I (also known as total current or melting current), base metal current $\mathbf{I}_{\mathbf{1}}$ and bypass current $\mathbf{I}_{\mathbf{2}}$ have also been denoted as $\mathbf{I}_{\mathbf{m}}, \mathbf{I}_{\mathbf{b m}}$ and $\mathbf{I}_{\mathbf{b p}}$ respectively in literature. They will be both used in order to match with the literatures cited.

The main loop represents the path through which the base metal current $\left(\mathrm{I}_{1}\right)$ flows while the bypass loop represents the path through which the bypass current $\left(\mathrm{I}_{2}\right)$ flows. In Figure 1 , the positive terminals of the two power supplies are connected together as a common positive terminal connecting to the main torch. The work-piece (or base metal) and bypass electrode are connected with the negative terminals of the main and bypass power supply 
respectively. This is a modification from the standard straight polarity GMAW system although is also possible from a reverse-polarity GMAW system.

In the system shown in Figure 1, the wire current

$$
I=I_{1}+I_{2}
$$

where $I$ is the total welding current that melts the wire. The division of the wire current $I$ into the base metal current $I_{1}$ and bypass current $I_{2}$ provides the double-electrode GMAW the fundamental to reduce the heat input into the work-piece while maintaining the melting speed.

For non-consumable DE-GMAW, the heat that melts the wire is

$$
H_{\text {wire }}=\left(V_{\text {anode }} I+k_{1} I^{2}\right) \Delta t
$$

where $V_{\text {anode }}$ is the anode voltage, $k_{1}>0$ is a constant, and $\Delta t$ is the time. In addition to $H_{\text {wire }}$ brought into the work-piece by the melted wire, the main arc also directly applies its cathode heat

$$
H_{\text {cathode }}=V_{\text {cathode }} I_{1} \Delta t
$$

into the work-piece. Omitting the resistive heat yields

$$
H_{\text {wire }} \approx V_{\text {anode }} I \Delta t
$$

Further, omitting the heat input into the work-piece due to the arc column radiation, the total heat input into the work-piece is

$$
H \approx\left(V_{\text {anode }} I+V_{\text {cathode }} I_{1}\right) \Delta t
$$

The range of the proportion $p$ of the wire melting heat in the total heat applied into the work-piece can be used to measure the controllability of the heat input of the process as quantified by:

$$
p=H_{\text {wire }} / H \approx V_{\text {anode }} I /\left(\left(V_{\text {anode }} I+V_{\text {cathode }} I_{1}\right)\right.
$$

For convenience, this paper refers $p$ as the deposition efficiency. A greater deposition efficiency $p$ implies a lower heat input procedure/process and a greater range of the deposition efficiency $p$ implies a better heat input controllability. It is apparent that $p$ increases as $I_{1}$ decreases (or $I_{2}$ increases) for the same $I$. By adjusting $I_{2}, p$ is adjusted and reaches the minimum

$$
p_{0}=V_{\text {anode }} /\left(V_{\text {anode }}+V_{\text {cathode }}\right)
$$

when $I_{1}=I$ or $I_{2}=0$, i.e., when the process becomes the conventional process. Hence, the non-consumable DE-GMAW can increase the melting speed without changing the heat input (or reduce the heat input without reducing the melting speed) and the increase in melting speed (or reduction in heat input) can be controlled by the bypass current.

For consumable DE-GMAW, the bypass wire is melted and the heat is added back into the work-piece such that

$$
\begin{aligned}
& H_{\text {wire }} \approx\left(V_{\text {anode }} I+V_{\text {cathode }} I_{2}\right) \Delta t \\
& H \approx\left(V_{\text {anode }}+V_{\text {cathode }}\right) I \Delta t
\end{aligned}
$$




$$
\begin{aligned}
p=\frac{H_{\text {wire }}}{H} & =\left(V_{\text {anode }} I+V_{\text {cathode }} I_{2}\right) /\left(V_{\text {anode }}+V_{\text {cathode }}\right) I \\
& =p_{0}+\Delta p
\end{aligned}
$$

where

$$
\Delta p=V_{\text {cathode }} I_{2} /\left(V_{\text {anode }}+V_{\text {cathode }}\right) I
$$

Again, when $I_{2}=0$, i.e., when the process becomes the conventional process, $\Delta p=0$. Hence, the consumable DE-GMAW can increase the melting speed without changing the heat input (or reduce the heat input without reducing the melting speed) and the increase in melting speed (or reduction in heat input) can be controlled by the bypass current.

\section{Non-Consumable DE-GMAW Using Constrained Bypass Arc}

A non-consumable DE-GMAW uses a non-consumable bypass electrode to realize the general DE-GMAW system in Figure 1. Its feasibility was first verified using a PAW torch to provide the non-consumable second electrode in 2004 at the University of Kentucky [17, 18] as shown in Figure 2. The use of PAW torch was to ease the establishment of the bypass arc because the pilot arc can easily provide a reliable channel to bridge the main arc with the tungsten second electrode. In fact, the constrained pilot arc can overcome the possible effects on the ignition of the bypass arc from variations in the bypass torch installation. . Hence, although the bypass arc can only be established after the main arc has been established, the existence of the bypass channel prior to the main arc is helpful for minimizing the delay from the establishment of the main arc to the establishment of the bypass arc. The DE-GMAW process can thus successfully established almost as soon as the main arc is ignited.

Two 12-X6-X0.5-in. plates were used to form a 60-deg groove as shown in Figure 3, and joined together using PAW as a root pass before being used as the work-piece for DEGMAW experiments. In the weld shown in Figure 3, the groove is sufficiently filled in a single pass at the travel speed of $6.6 \mathrm{in} / \mathrm{min}$ with a bypass current at $100 \mathrm{~A}$. Under the same welding conditions (same main wire feed speed and same travel speed), the work-piece was burned through in the conventional GMAW process. The effectiveness of the bypass method for heat input and arc pressure reductions without reducing the melting speed is demonstrated. 


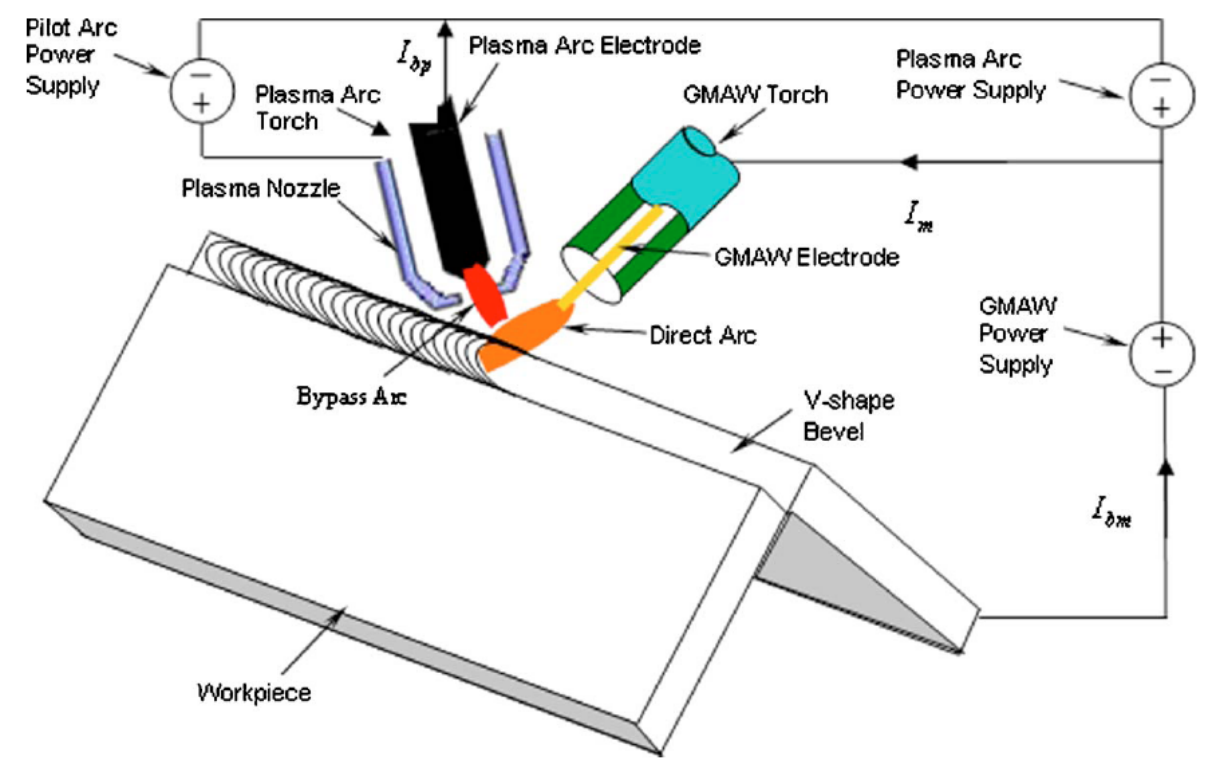

Figure 2 Non-consumable DE-GMAW experimental system using a PAW torch [17]. $\mathbf{I}_{\mathbf{m}}$, $\mathbf{I}_{\mathbf{b m}}$, and $\mathbf{I}_{\mathbf{b p}}$ stand for the melting, base metal and bypass current respectively and correspond to $\mathbf{I}, \mathbf{I}_{\mathbf{1}}$ and $\mathbf{I}_{\mathbf{2}}$ respectively in Figure 1.

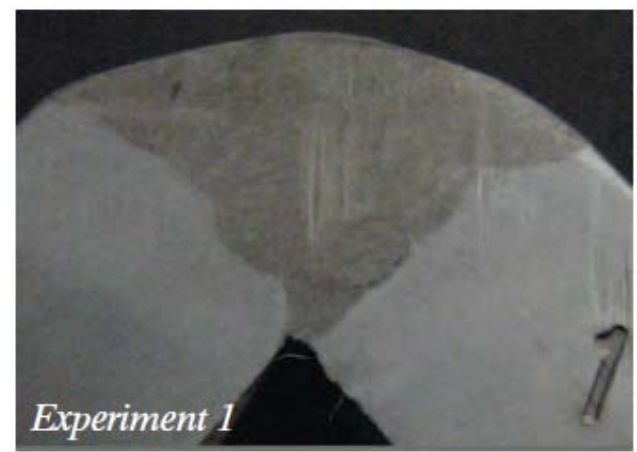

Figure 3 Cross-section of weld made by non-consumable DE-GMAW using plasma bypass arc. $I_{b p}=100 \mathrm{~A}, I_{b m}=145 \mathrm{~A}$ [17].

\section{Non-Consumable DE-GMAW Using Unconstrained Bypass Arc}

While the pre-existence of a constrained pilot arc can ease the ignition of the bypass arc after the main arc has been established, its associated high cost for the equipment and the inconvenient large size of the bypass torch are all unwanted. In the non-consumable DEGMAW system shown in Figure 4, the PAW torch in Figure 2 is replaced by a GTAW torch. The bypass power supply is replaced by a bypass control circuit which controls the passing bypass current at the desired level. The main GMAW power supply provides $I_{m}=$ $I_{b m}+I_{b p}$, i.e., $I=I_{1}+I_{2}$ in Figure 1 . Since the tungsten electrode is much easier to emit electrons then the work-piece, the majority of the current provided by the power supply would be bypassed such that the bypass current may exceed the desired level. The bypass 
control circuit provides an approach to reduce the bypass current to its desired level. The current principle $I=I_{1}+I_{2}$ of DE-GMAW as shown in Figure 1 is unchanged.

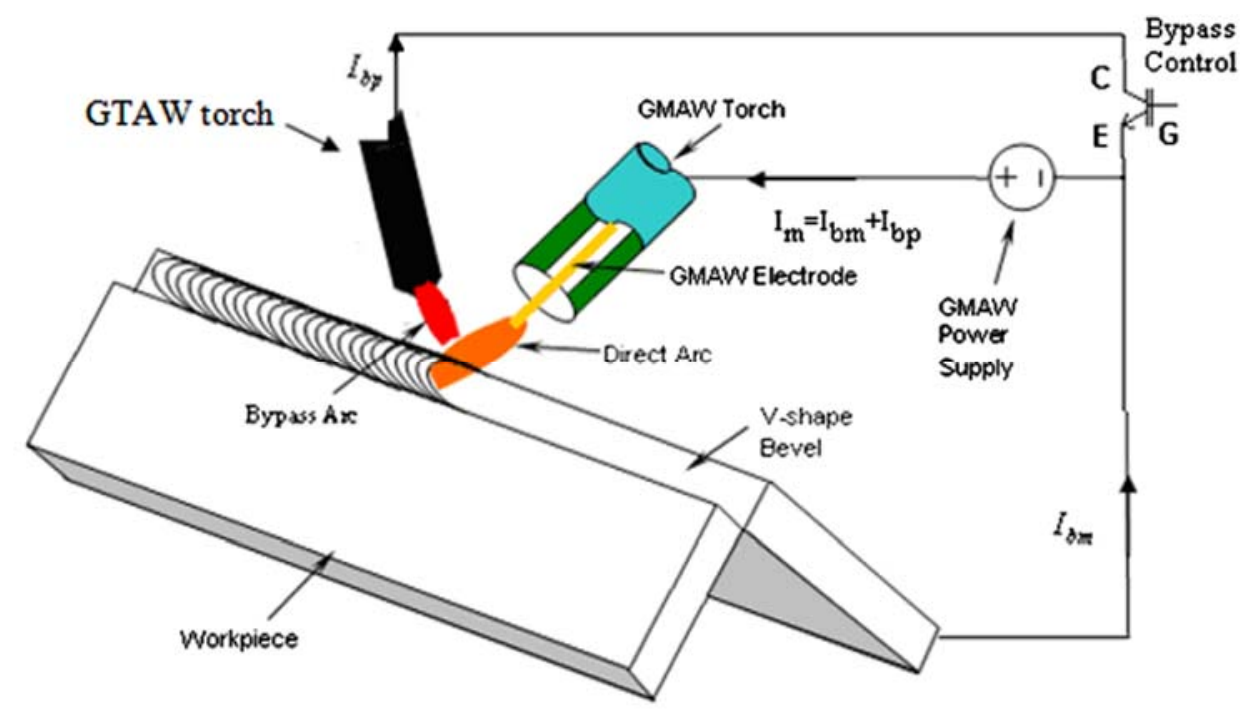

Figure 4 Principle of non-consumable DE-GMAW [17]

In the system in Figure 4, the bypass control circuit is an Insulated Gate Bipolar Transistor (IGBT) which controls the on and off of the bypass loop. However, if no current sensors are used to provide the feedback to control the switch of the IGBT, this non-consumable DE-GMAW system would work in the open loop mode. Proper welding parameters, especially the proportion of the on-off ratio and the wire feed speed which controls the total current, must be set carefully to obtain the currents at their desired levels.

The non-consumable DE-GMAW circuit was analyzed as shown in Figure 5 [17]. The GMAW (main) arc and bypass arc were represented by their equivalent resistances. The two arcs are approximated as two resistors in parallel with the same voltage. The current distribution is thus determined by their resistances. Their corresponding current will be inversely proportional to their resistance. Since the equivalent resistance of the bypass arc is much smaller, an adjustable power resistor should be added to control the bypass current. On the other hand, the total current is determined by the wire feed speed. The currents can therefore be controlled in reasonable ranges. 


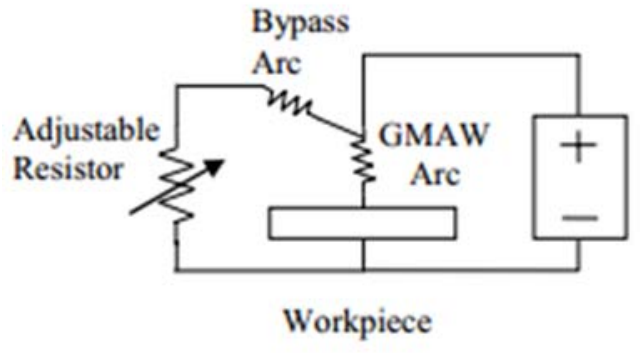

(a)

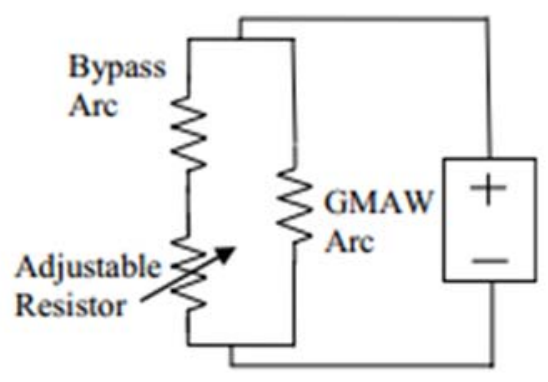

(b)

Figure 5 Equivalent circuit of a single power supply based non-consumable DE-GMAW system [18].

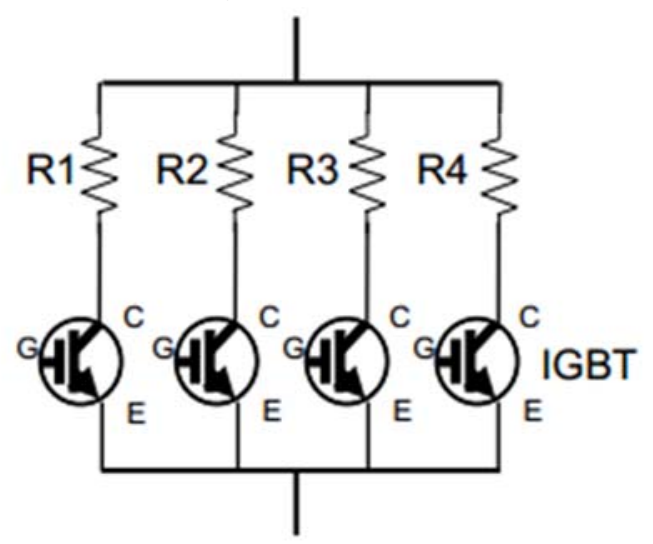

Figure 6 Adjustable resistor [18]

The adjustable power resistor has been formed using four parallel power resistors with each in series with an IGBT (see Figure 6) as its on-off control switch [18]. The resistance for each resistor has been designed such that the parallel circuit can provide adequate resolution for the resultant resistance incorporated with the on-off switch of the resistors. Figure 7 shows the recorded currents for a control experiment using the non-consumable DE-GMAW process and control system shown in Figures 4-6. 


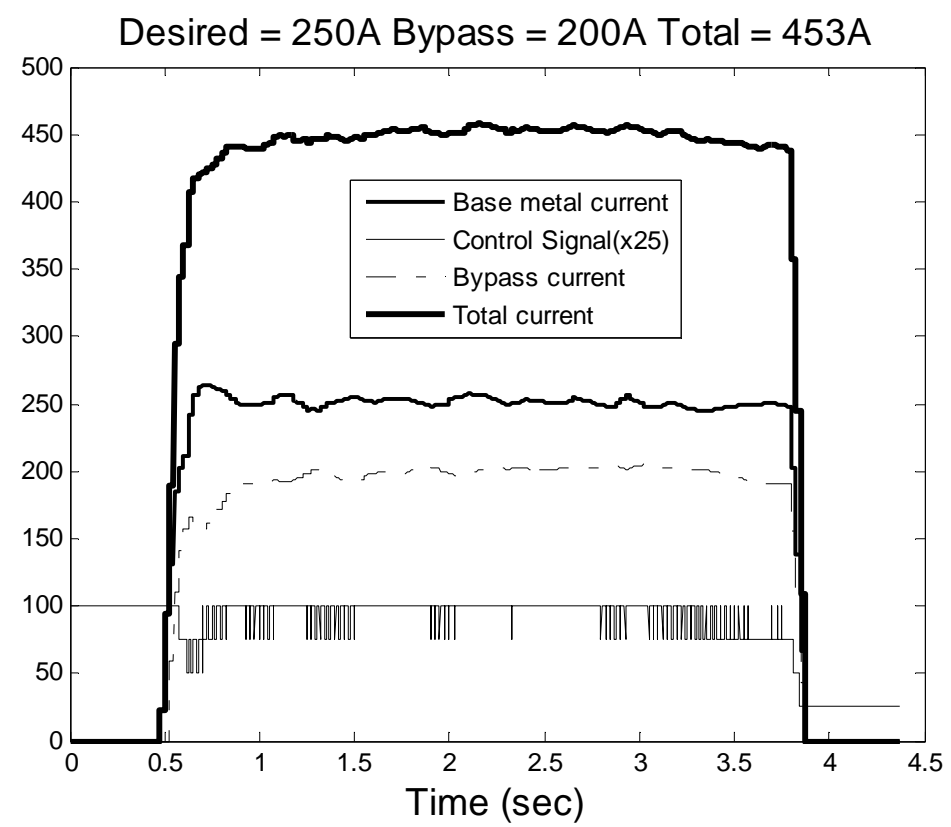

Figure 7 A control example [18]. The bypass current is adjusted by changing the equivalent resistance of the power resistor to maintain the base metal current around the desired value that is $250 \mathrm{~A}$.

Figure 8 shows an example weld made on a lap joint, formed by $2 \mathrm{~mm}$ on $2 \mathrm{~mm}$ thick low carbon steel sheet, with the non-consumable DE-GMAW process and control system shown in Figures 4-6. The travel speed was $1.65 \mathrm{~m} / \mathrm{min}$ (65 IPM) while the wire was fed in at $14.0 \mathrm{~m} / \mathrm{min}$ (550 IPM). The welding voltage was 32 volts. From this example weld, it can be seen that the DE-GMAW process made acceptable weld at a high speed. However, when applying the conventional GMAW by setting the bypass current to zero, the lap-joint formed by two $2 \mathrm{~mm}$ low carbon steel sheets was burned through [18].

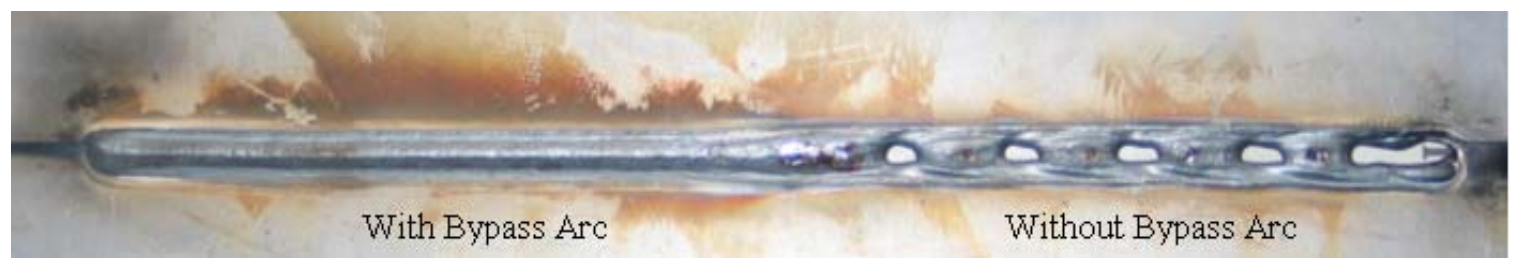

Figure 8 Comparison of weld on lap joint made by controlled DE-GMAW and conventional GMAW process [18]. 


\section{Metal Transfer in Non-Consumable DE-GMAW Using Unconstrained Bypass Arc}

The American Welding Society (AWS) classifies the metal transfer into three primary modes: spray transfer, globular transfer, and short-circuiting transfer. In the spray transfer, the liquid metal droplets transfer into the weld pool across the arc gap with diameters similar to or smaller than that of the wire. The International Institute of Welding (IIW) further classifieds the spray transfer mode into the projected spray (or drop spray), streaming spray, and rotating spray. In the globular transfer, the liquid metal droplets are also transferred across the arc gap but with diameters much greater than that of the wire. In the short-circuiting transfer, the melted metal is transferred when the droplet is in contact with the weld pool. For conventional GMAW, metal transfer plays a critical role in determining the arc stability and weld quality. In DE-GMAW, the dependence of the arc stability and weld quality on the metal transfer still exists.

A major issue in GMAW is that it requires a current higher than the critical current [19] to produce the desired spray mode. However, such a high current may not be desired by the application. Specifically, in conventional GMAW, the current flows from the wire approximately around the wire axial direction. This direction determines the net effect of the electromagnetic force - the major detaching force, needed to produce the spray transfer. Under this condition, the current needs to be greater than the critical current in order to supply a sufficient detaching force for the spray transfer. However, in DE-GMAW, the current from the wire flows into two directions: around the wire axial direction and toward the bypass electrode. The condition in the conventional GMAW that determines the net effect of the distributed electromagnetic force field as the detaching force is changed. The metal transfer in DE-GMAW should be related to both the base metal current and bypass current [20-22].

Studies found that, when the total current is high enough, the droplet forms a stream which bridges the electrode wire and the weld pool. Partial welding current can flow through the stream to the work-piece. However, the current path from the solid electrode wire to the work-piece still exists because of the existence of the main arc. This is a metal transfer that falls into the definition of neither the free flight transfer nor the bridge transfer. It has been referred to as the contacting stream spray transfer because of its similarity to the conventional stream spray transfer and the conventional short-circuiting transfer.

In greater detail, when the bypass arc is present, partial melting current is forced to flow to the bypass electrode. Because the bypass tungsten electrode is at a different direction from the cathode on the work-piece, the bypass current forms an angle with the base metal current which flow from the droplet to the cathode on the work-piece. As a result, the 
convergence of the current in conventional GMAW is undermined so that the net electromagnetic force shifts toward becoming a detaching force. Hence, although the total current may be smaller than the critical current, the metal transfer still changes to the spray mode after the bypass arc is introduced. In addition to the change of the transfer mode, the effect of the bypass arc on the droplet trajectory can also be observed.

In the series of experiments shown in Figure 9 [20], the total current is approximately the same (the wire feed speed is the same) but the bypass current varies. It can be seen that the droplets associated with the higher bypass current changed from globular transfer to spray transfer and became smaller with higher droplet rate. This suggests that the electromagnetic force was further shifted toward being a detaching force although the total current remained unchanged.

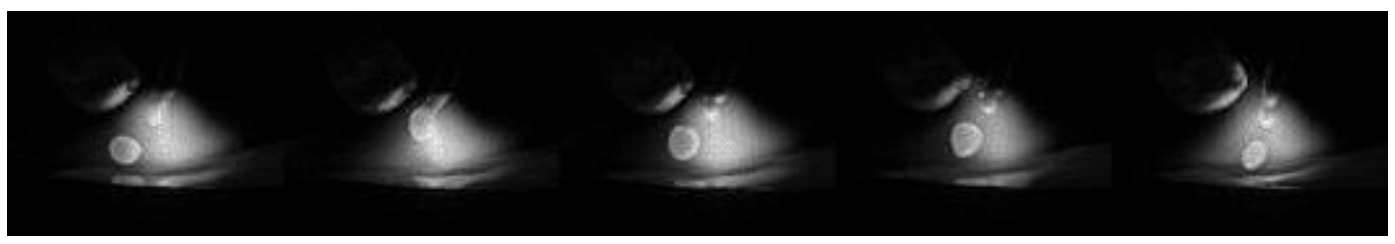

(a) Bypass current $=0$

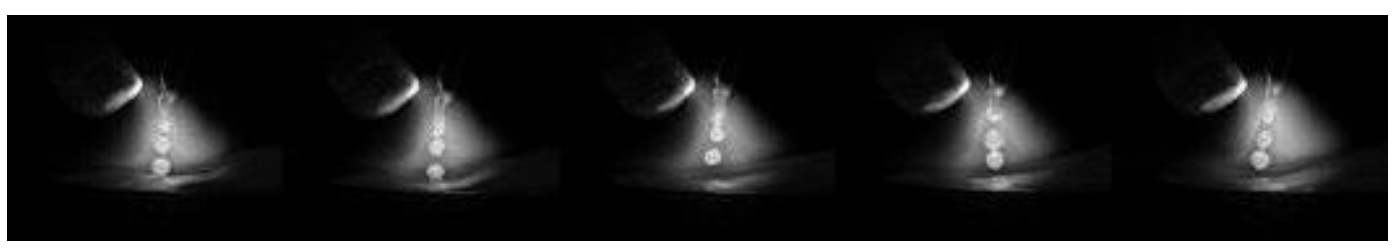

(b) Bypass current $=72 \mathrm{amps}$

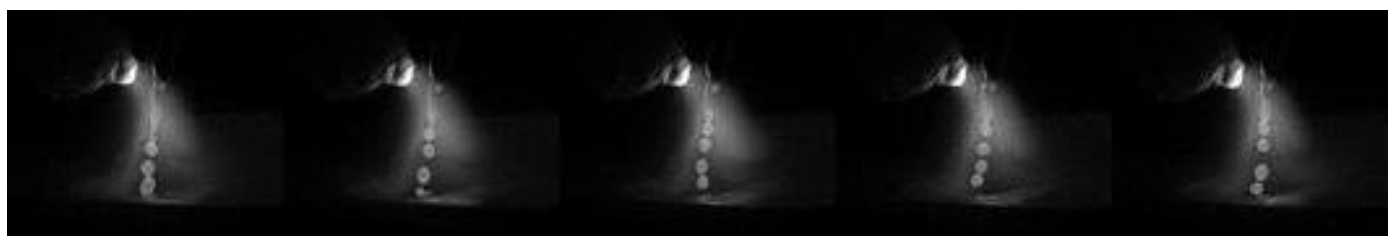

(c) Bypass current $=108 \mathrm{amps}$

Figure 9 Metal transfer experiments. WFS: $6.4 \mathrm{~m} / \mathrm{min}$ (250IPM), diameter $1.2 \mathrm{~mm}$ steel wire. (a), (b), and (c) used different bypass currents.

\section{Consumable DE-GMAW and Analysis [23, 24]}

In non-consumable DE-GMAW, although extra heat input and arc force have been reduced, the energy absorbed by the bypass electrode is wasted. If the bypass electrode is a consumable wire, the waste can be eliminated while still providing the advantages associated with DE-GMAW. The resultant process is the consumable DE-GMAW shown 
in Figure 10 and its heat input controllability as represented by the range of the deposition efficiency $p$ has been discussed earlier in Section 2 and especially mathematically analyzed in Eq. (8)-(11). The consumable wire is fed through a GMAW torch as the bypass electrode. In Figure 10, two power supplies running at the CV mode are used to provide the base metal and bypass current. The main wire is primarily melted by the anodes of the main arc and bypass arc whose currents are the base metal current and bypass current respectively. The bypass wire is primarily melted by the cathode of the bypass arc. The main wire feed speed thus controls the sum of the base metal and bypass current, i.e., the total current $I=$ $I_{1}+I_{2}$, and the bypass wire feed speed determines the bypass current $I_{2}$.

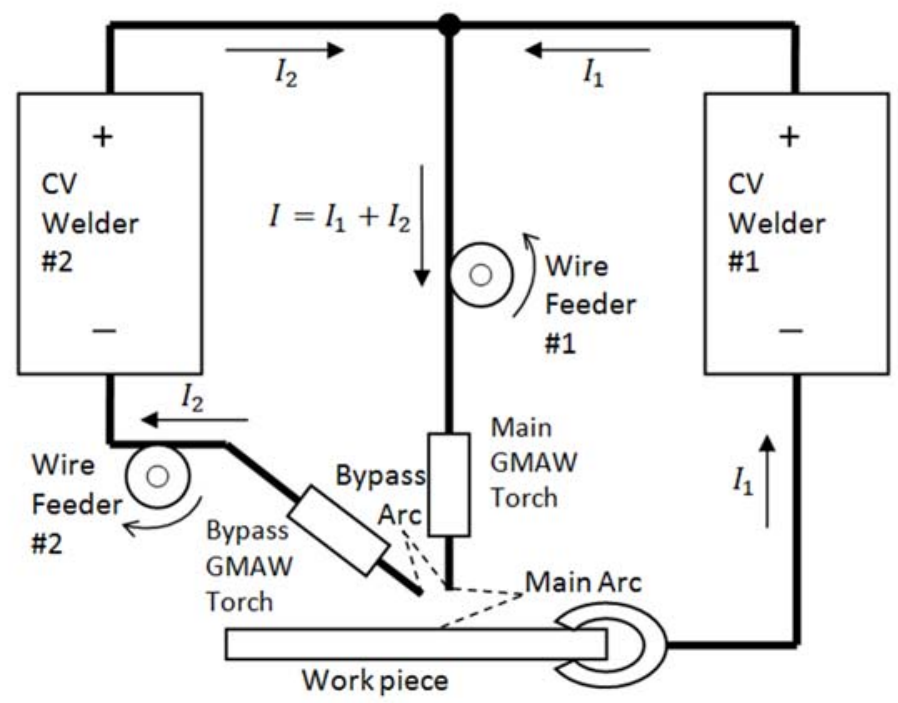

Figure 10 Principle of consumable DE-GMAW

In Figure 10, two CV power supplies are used. In such a CV power supply based system, the total current and bypass current depend on the corresponding wire feed speed and voltage setting. First, the CV mode controls the length of the main arc, at a desired level corresponding to the setting of CV Welder \#1 in Figure 10, to balance the melting with the feeding of the main wire. The actual total current is the result of the adjustment on the melting current for the main wire. In the meantime, the actual bypass current is the result of the adjustment on the melting current for the bypass wire. When the actual bypass current is determined by the need to balance the melting and feeding for the bypass wire, the balance of the main wire determines the base metal current. Hence, balancing the melting with feeding for the two wires controls the base and bypass current. Second, the equilibriums, as determined by the voltage settings of the two CV power supplies, control the degrees of the balances. This is because that the realized arc lengths as a result of the balances affect the wire extensions and the wire extensions determine the resistive heats on the wires. As the resistive heats increase, the needed heats from the arc anodes to balance the corresponding melting with feeding are reduced. The corresponding currents are thus 
reduced. Hence, both the currents are controlled by the wire feed speeds and voltage settings. However, the actual currents are not accurately controlled and also depend on other variables including the tip-to-work distance (for the main arc) and the positioning of the bypass wire in relation to the main wire (for the bypass arc).

There are three major parameters that determine the resultant welds from DE-GMAW: base metal current, heat input, and mass input. Ideally, one needs a certain amount of metal be deposited on the joint to form a weld with the desired shape and penetration. When the mass input and joint geometry are given, the weld shape and penetration are primarily determined by the penetration capability of the arc. For DE-GMAW, this penetration capability is determined by the heat input and the force of the main arc. The heat input consists of the heat input from the droplets and the heat input directly imposed on the workpiece. When the mass input is given, the heat input from the droplets is approximately fixed. The heat input directly imposed on the work-piece is due to the cathode heat of the main arc determined by $V_{\text {cathode }} I_{1}$ and is thus controlled by the base metal current $I_{1}$ since $V_{\text {cathode }}$ is a constant. On the other hand, the force of the main arc is proportional to the square of the base metal current $I_{1}$. Hence, when the mass input is given such that the heat input is approximately given, the resultant weld is controlled by the base metal current. However, while the mass input can be controlled, the CV power supply based system shown in Figure 10 does not provide an accurate control on the base metal current.

\section{Control of Consumable DE-GMAW}

A method to produce desired welds is to control the base metal current and bypass current at desired levels such that the heat input determined by the total current (their sum) and penetration capability determined by the base metal current and heat input are accurately controlled. When CV power supplies are used, these two currents may be adjusted by their corresponding wire feed speeds in large ranges. The adjustments on the wire feed speeds affect the total mass input but it may be acceptable as long as the required minimal mass be deposited.

Figure 11 shows a method which feedback controls the base metal current by adjusting the main wire feed speed such that the base metal current may be adjusted in a large range. This is needed because the base metal current not only contributes to the total heat input but also is the most critical parameter to control the penetration capability when the mass and heat input are in a certain range. The bypass voltage is feedback controlled using the $\mathrm{CV}$ mode bypass power supply which adjusts the bypass current. The bypass current is changed such that the heat input is changed. However, the adjustment range for the bypass

current, thus the heat input, is relatively small because the bypass wire feed speed is not changed. For open arc (rather than submerged arc) consumable DE-GMAW, the stability of the bypass arc relies on its arc length. Hence, the control system provides an accurate 
control on the arc pressure, an accurate control on the bypass arc stability which is critical for consumable DE-GMAW especially when the bypass arc is open, and approximate controls on the mass and heat input.

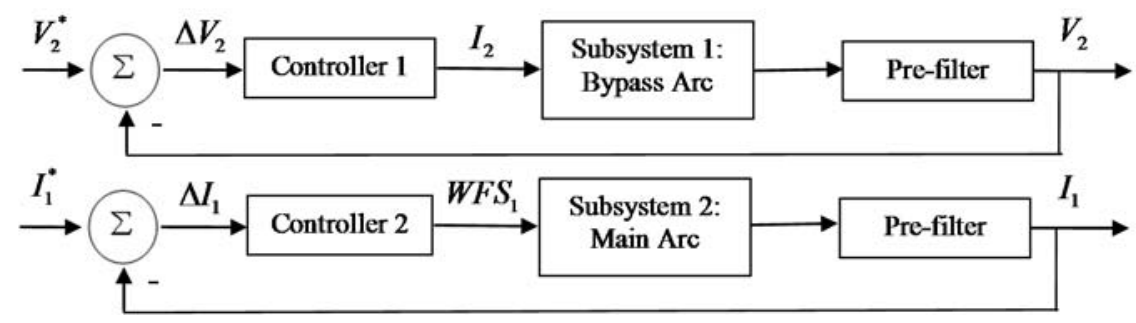

Figure 11 A control for two CV power supply based consumable DE-GMAW system [25]

The design of the control system in Figure 11 needs the process being controlled to be modeled. As in conventional GMAW, the main arc voltage $V_{1}$ is also automatically feedback controlled in the DE-GMAW process by the CV welder, and the location of the main wire tip is approximately fixed. The length of the bypass arc $\left(l_{2}\right)$, i.e., the distance from the bypass wire tip to the main wire, is determined by the balance between the melting and feeding of the bypass wire:

$$
\frac{d l_{2}}{d t}=\left(v_{m 2}-W F S_{2}\right) \sin \theta
$$

where $v_{m 2}$ is the melting speed of the bypass wire; $\theta$ is the angle between the two wires; and $\sin \theta$ projects the bypass wire (length) to the direction of the bypass arc. When the given wire feeding speed $W F S_{2}$ is balanced by the melting speed $v_{m 2}, \frac{d l_{2}}{d t}=0$.

The melting speed $v_{m 2}$ is determined by the bypass arc cathode power $I_{2} V_{\text {cathode }}$ and the resistive heating power $r I_{2}^{2}$, where $r$ is the resistance of the wire extension carrying the bypass current $I_{2}$. The resistance $r$ is proportional to the length of the wire extension $\left(E_{2}\right)$. It has been proved $[26,27]$ that the melting speed of a wire in GMAW can be expressed as $k_{1} I+k_{2} E I^{2}$ where $k_{1}$ and $k_{2}$ are constants and $E$ is the length of the wire extension. Hence, the melting speed for the bypass wire is

$$
v_{m 2}=a_{1} I_{2}+a_{2} E_{2} I_{2}^{2}
$$

where $a_{1}$ and $a_{2}$ are constants. When the welding arc is stable, the melting speed is equal to the wire feed speed: 


$$
W F S_{2}=v_{m 2}=a_{1} I_{2}+a_{2} E_{2} I_{2}^{2}
$$

If the bypass current (the control variable in subsystem 1) is changed to $I_{2}+\Delta I_{2}$ from $I_{2}$, the equilibrium will be broken and the melting speed becomes

$$
\begin{aligned}
& v_{m 2}=a_{1}\left(I_{2}+\Delta I_{2}\right)+a_{2}\left(E_{2}+\Delta E_{2}\right)\left(I_{2}+\Delta I_{2}\right)^{2} \\
& \cong\left(a_{1} I_{2}+a_{2} E_{2} I_{2}^{2}\right)+\left(a_{1}+2 a_{2} E_{2} I_{2}\right) \Delta I_{2}+a_{2} I_{2}^{2} \Delta E_{2} \\
& =W F S_{2}+\left(a_{1}+2 a_{2} E_{2} I_{2}\right) \Delta I_{2}+a_{2} I_{2}^{2} \Delta E_{2}
\end{aligned}
$$

where high order deviations have been omitted. Thus, Eq. (12) can be written as

$$
\frac{d l_{2}}{d t}=\left(a_{1}+2 a_{2} E_{2} I_{2}\right) \Delta I_{2} \sin \theta+a_{2} I_{2}^{2} \Delta E_{2} \sin \theta
$$

after the bypass current is changed. Because the arc voltage is a linear function of the arc length and $\Delta V_{2} \propto-\Delta E_{2} \sin \theta$ where $\Delta V_{2}$ is the deviation of the bypass arc voltage from its previous value $V_{2}$ at the equilibrium, model (16) can thus give

$$
\frac{d\left(V_{2}+\Delta V_{2}\right)}{d t}=\frac{d \Delta V_{2}}{d t}=\lambda \frac{d l_{2}}{d t}=k \Delta I_{2}-\alpha \Delta V_{2}
$$

where $k, \lambda$, and $\alpha$ are coefficients. Hence

$$
\frac{d \Delta V_{2}}{d t}+\alpha \Delta V_{2}=k \Delta I_{2}
$$

Subsystem 1 can thus be approximated as a first order model but the model parameters depend on the manufacturing condition parameters, such as $E_{2}, I_{2}, \theta$, etc. as can be seen from Eq. (16).

Using the control system, satisfactory welds have been made [25].

\section{Double-Electrode Submerged Arc Welding (DE-SAW) [27]}

Submerged arc welding (SAW) is a variant of GMAW which allows the use of extra high currents to deposit metals at high speeds. The major issue associated with high currents and high deposition speeds is the associated large heat input which causes large distortion whose correction is highly costly. An extension of the DE-GMAW into SAW may result in desirable heat input and distortion reductions. The resultant variant is referred to as DESAW. 
Figure 12 shows a DE-GMAW system developed at the Adaptive Intelligent Systems LLC especially for shipbuilding where SAW is extensively used. The tractor together with the main wire feeder and main torch it carries and moves is considered existing equipment manufacturers already have for their existing SAW process. To form the DE-SAW system, a bypass torch is added and attached to the main torch and a power supply is added. In addition, the embedded control system together with the current sensors is added to form a controlled DE-SAW process/system.

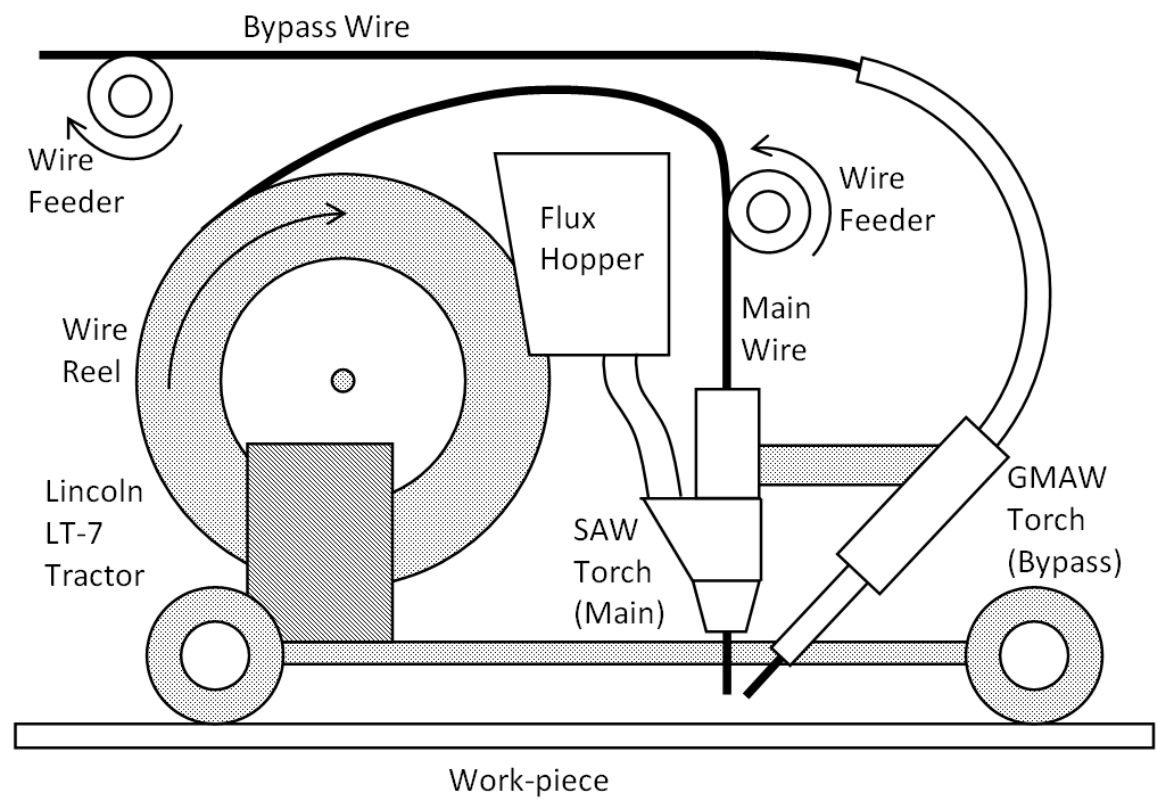

(a) System diagram

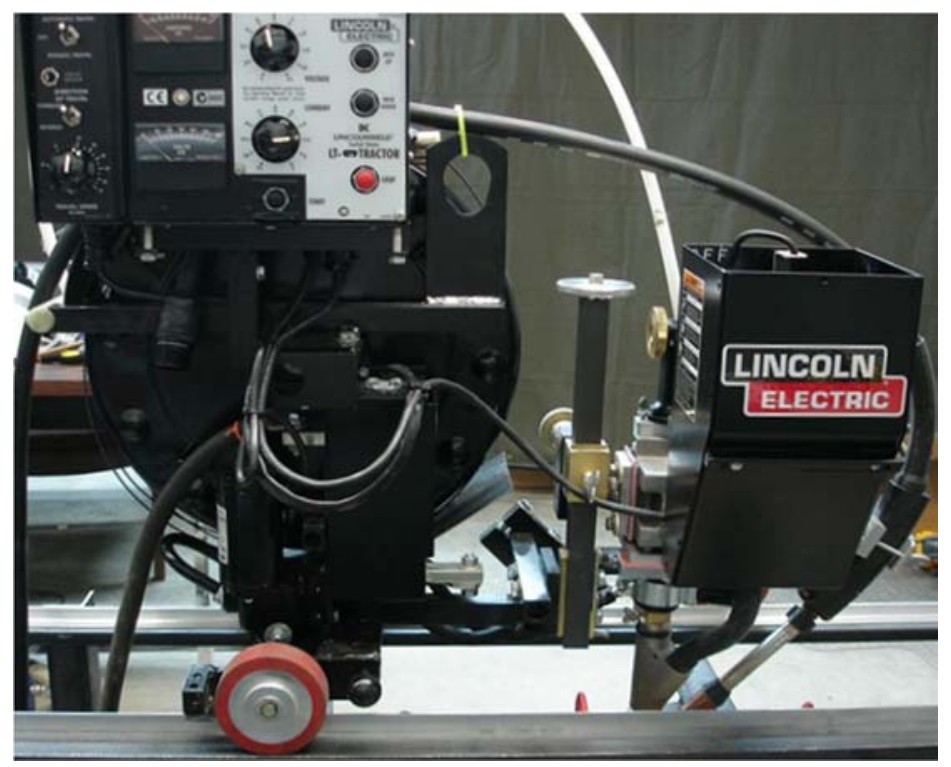

(b) System photograph [27] 


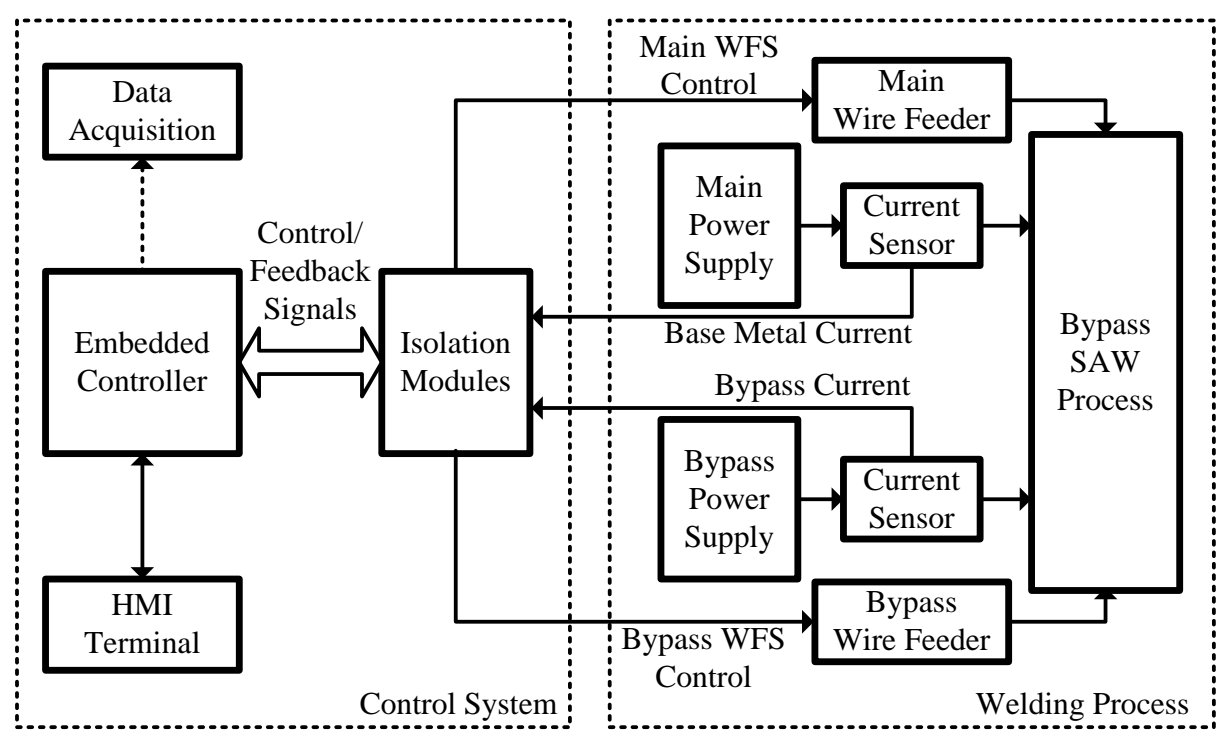

(c) Control system diagram [27]

Figure 12 A DE-SAW system.

Because of possible large variations in manufacturing environment, the wire feed speeds are adjusted to feedback control the base metal and bypass currents. For submerged arc, the stability of the arcs is easier to maintain than those in open arc environment as in GMAW and DE-GMAW. The stability of the arcs is thus controlled by setting the voltages to selected values. The adjustments on the wire feed speeds change the mass input but they should be acceptable as long as the minimal mass input requirement is met and the heat inputs and arc pressure (thus the penetration capability) are accurately controlled by maintaining the currents at desired levels. Welds with desired heat input, shape and penetration can thus be produced with such controlled DE-SAW process.

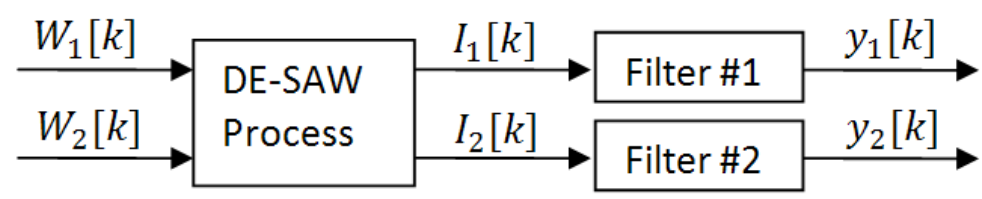

Figure 13 Block diagram of DE-SAW control system

Figure 13 shows a coupled two-input two-output system in which the two wire feed speeds are chosen as the system inputs and the filtered base metal current and bypass current, denoted as $\mathrm{y}_{1}$ and $\mathrm{y}_{2}$, are the system outputs. This system may be modeled as:

$$
\begin{gathered}
\mathrm{y}_{1}[\mathrm{k}]=\mathrm{y}_{1}[\mathrm{k}-1]+\mathrm{h}_{1} \Delta \mathrm{W}_{1}[\mathrm{k}-1]+\mathrm{h}_{2} \Delta \mathrm{W}_{1}[\mathrm{k}-2]+\cdots+\mathrm{h}_{\mathrm{N}} \Delta \mathrm{W}_{1}[\mathrm{k}-\mathrm{N}]+ \\
\mathrm{g}_{1} \Delta \mathrm{W}_{2}[\mathrm{k}-1]+\mathrm{g}_{2} \Delta \mathrm{W}_{2}[\mathrm{k}-2]+\cdots+\mathrm{g}_{\mathrm{N}} \Delta \mathrm{W}_{2}[\mathrm{k}-\mathrm{N}]
\end{gathered}
$$




$$
\mathrm{y}_{2}[\mathrm{k}]=\mathrm{y}_{2}[\mathrm{k}-1]+\mathrm{p}_{1} \Delta \mathrm{W}_{2}[\mathrm{k}-1]+\mathrm{p}_{2} \Delta \mathrm{W}_{2}[\mathrm{k}-2]+\cdots+\mathrm{p}_{\mathrm{N}} \Delta \mathrm{W}_{2}[\mathrm{k}-\mathrm{N}]
$$

Equations (17) and (18) together constitute the dynamic incremental model of the DESAW process. System order "N" and parameters $h_{j}, g_{j}, p_{j}(j=1,2, \ldots, N)$ can be obtained using data from welding experiments that produce sampled and filtered currents $\mathrm{y}_{1}$ and $\mathrm{y}_{2}$ from the applied $W_{1}$ and $W_{2}$. " $k$ " stands for the present discrete-time instant and " $k-j$ " $(\mathrm{j}=1, \ldots, \mathrm{N})$ are the previous instants.

The model predictive control (MPC) [28-30] is considered the only advanced control method which has gained reasonable applications in industry. This advanced control method can be explained with the following five steps for the DE-SAW process as modeled by (17) and (18):

1. Predicting the system outputs $j$-step-ahead $(j=1, \ldots, N)$ using the dynamic incremental model given in Equations (17) and (18) as functions of the changes to be taken in the wire feed speeds for the present time, i.e., as functions of $\Delta W_{1}[k]$ and $\Delta W_{2}[k]$ without applying further future changes (constant future) in wire feed speeds;

2. Creating desired trajectories for output signals $\left(y_{1}\right.$ and $\left.y_{2}\right)$ of the controlled plant to transit from their present values to the desired values;

3. Forming a cost function using the squared differences between the predicted outputs and the trajectories for the future " $N$ " steps. Penalties can be added to penalize fast changes in the wire feed speeds. The cost function will be a quadratic function of $\Delta W_{1}[k]$ and $\Delta W_{2}[k]$.

4. Finding the control law by minimizing the cost function with respect to $\Delta W_{1}[k]$ and $\Delta W_{2}[k]$.

5. Moving forward to the next control cycle, and repeating the prediction and control law recursively.

While submerging the arcs helps maintain the arc stability, the extra-high travel speed needed for DE-SAW applications as in shipbuilding applications and the need to minimize the heat input for distortion minimization cause process variations as well as the need for high speed accurate adjustments. To meet the challenges, the MPC is proposed as a compromise to balance among the needed control speed, control accuracy and robustness to process variations. An appropriately controlled DE-SAW process has developed at the Adaptive Intelligent Systems LLC and become a standard tool to address the needs from shipbuilding applications. 


\section{Applications of Controlled DE-SAW}

\subsection{Penetration Depth Control [27]}

A number of studies have been devoted to modeling the SAW process [31-35]. Based on these studies, a comprehensive model has been proposed to correlate the depth of the weld penetration to a number of welding parameters as the regression variables:

$$
P=f\left(I_{b m}, W_{t}, G, C T W D, S\right)
$$

Here $P$ is the depth of partial penetration weld (in.), $I_{b m}$ the base metal current (A), $W_{t}$ the total deposition speed (lb/hour), $G$ the gap of the joint (in.), CTWD the contact-tip-to-work distance (in.), and $S$ the travel speed (IPM or inch per minute).

In the welding parameters included in (19), CTWD and $S$ can be accurately controlled and $G$ may be controlled with a certain range. The approach is thus to simplify the model into the following form

$$
P=f\left(I_{b m}, W_{t}\right)
$$

to identify the model under given CTWD, $S$ and nominal $G$, and then examine how the accuracy may be affected by $G$ when it is in the tolerant range. It is apparent that

$$
W_{t}=W_{m}+W_{b p}
$$

Here $W_{m}$ and $W_{b p}$ are the deposition rates from the main (SAW) wire and bypass wire respectively. In general, a deposition speed $W$ can be calculated from its wire feed speed $W F S$ for a steel wire in the following expression.

$$
W=13.1 \times D^{2} \times W F S \times E E
$$

Here D is the diameter of the wire (in.), WFS the wire feed speed (IPM), and EE the electrode efficiency that is considered $100 \%$ for a solid wire. The constant of 13.1 is due to the density and the units used. Hence,

$$
W_{t}=W_{m}+W_{b p}=13.1 \times\left(D_{m}^{2} \times W F S_{m}+D_{b p}^{2} \times W F S_{b p}\right)
$$

The proposed model thus becomes

$$
P=f\left(I_{b m}, W_{m}, W_{b p}\right)
$$

This is a result of analysis based on process physics for possible variables that may affect the penetration depth. However, it is still yet to know if each possible variable actually affects the penetration depth significantly and how it affects. To this end, experiments have 
been conducted and the recorded variables and measured penetration depths have been used to fit various possible models. It was found that, when other parameters including $W_{m}$ and $W_{b p}$ are in certain ranges, the penetration depth only depends on the base metal current $I_{b m}$. The relationship between the penetration depth and the base metal current can be best described by the following global model:

$$
P=-0.1258+0.0008 I_{b m}
$$

where the penetration depth $P$ and current $I_{b m}$ are measured by inch and A respectively when $I_{b m}$ is in the range [237 A, $577 \mathrm{~A}$ ] and low carbon steel plates of 0.5 inch thickness are butt welded with no intentional gap.

When the intended penetration depth is in a smaller range such that the parameters reduce their ranges and the material is given, local models can be established to improve the accuracy. For butt welding on $1 / 2$ inch $(12.7 \mathrm{~mm})$ thick DH 36 plates with no intentional gap, $50 \%$ intended penetration depth, i.e., 0.25 inch or $6.4 \mathrm{~mm}$, resulted in the following local model:

$$
P=-0.3633+0.001312 \times I_{b m}
$$

75\% intended penetration depth resulted in local model:

$$
P=-0.4942+0.001312 \times I_{b m}
$$

The maximum error is 0.051 ” for $1 / 4$ " ( $50 \%$ partial penetration) intended penetration or $2.05 \%$ of desired penetration depth and 0.0041 " for $3 / 8$ " (75\% partial penetration) intended penetration or $1.10 \%$ of required penetration depth, both being inside the tolerated error of $1 / 16$ " set by shipyards. The penetration depth has been successfully controlled as demonstrated in Figure 14.

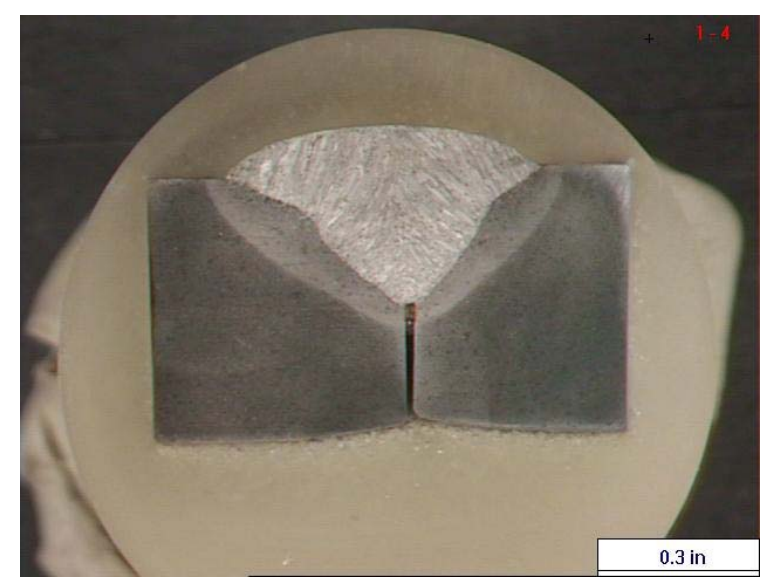

(a) Weld bead profile for $1 / 4$ " partial penetration. 


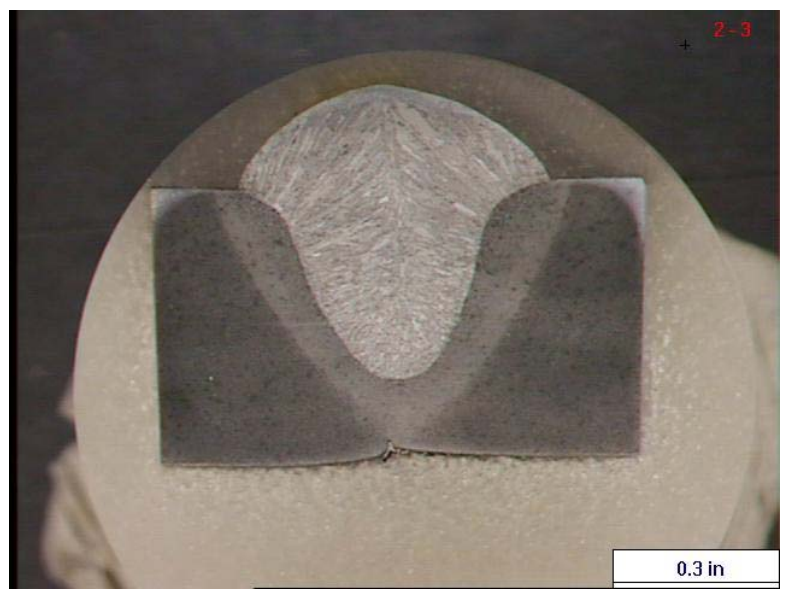

(b) Weld bead profiles for 3/8”partial penetration.

Figure 14 Cross section of welds from penetration control system

\subsection{Heat Input Reduction in Fillet Welding}

DE-GMAW including DE-SAW is characterized by its capability to despite materials with reduced heat input. However, for a specific application, a certain penetration capability is needed to produce the desired weld bead shape and fusion. A needed amount of metals may be deposited by the DE-SAW with reduced heat input but the degree of the allowed reduction in the heat input is determined by the application. The resultant distortion reduction is thus affected.

An effective way is thus to find acceptable methods to reduce the heat input needed to produce the desired weld bead and penetration and then use the DE-GMAW or DE-SAW process to realize this reduction while maintaining the needed deposition.

The Adaptive Intelligent Systems LLC developed a method to reduce the heat input needed for fillet welding. Figure 15 marks the leg size of the fillet weld. In most cases, both leg sizes need to be no less than the thickness of the plate. To deposit sufficient amount of melted wire to form welds meeting the size requirement, conventional SAW uses relatively large currents causing large heat input and distortion. When using DE-SAW, if the heat input is reduced significantly, welds with shape shown in Figure 16(a) may be produced. The weld is too convex such that the leg size does not increase as much as desired with the increased amount of deposited metal. Further, the re-entrant angle is reduced and may fall below 90 degree failing to meet the requirement. The cause is that the penetration capability is reduced when the heat input is reduced but the needed penetration capability to produce a flat (not significantly convex) weld is unchanged. To solve the problem, a gap shown in Figure 15 is introduced. For 3/16 inch thick plates, if the gap is less than $1.8 \mathrm{~mm}$, the 
required leg size will be unchanged. Hence, the modified joint design with $1.5 \mathrm{~mm}$ gap shown in Figure 15 is proposed for the use of DE-SAW in fillet welding.

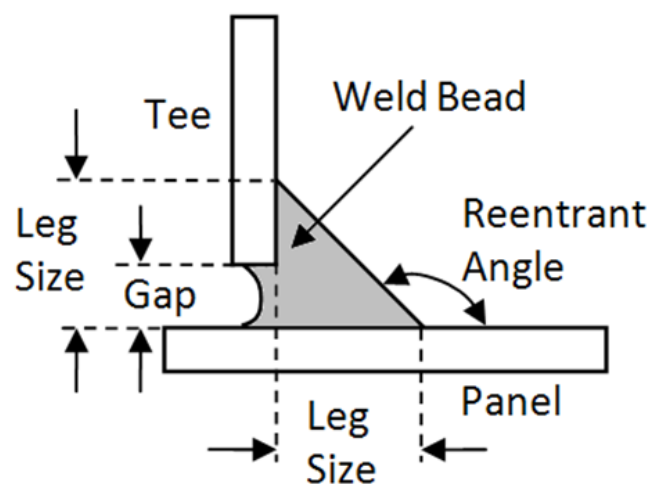

Figure 15 Modified fillet joint design with a gap

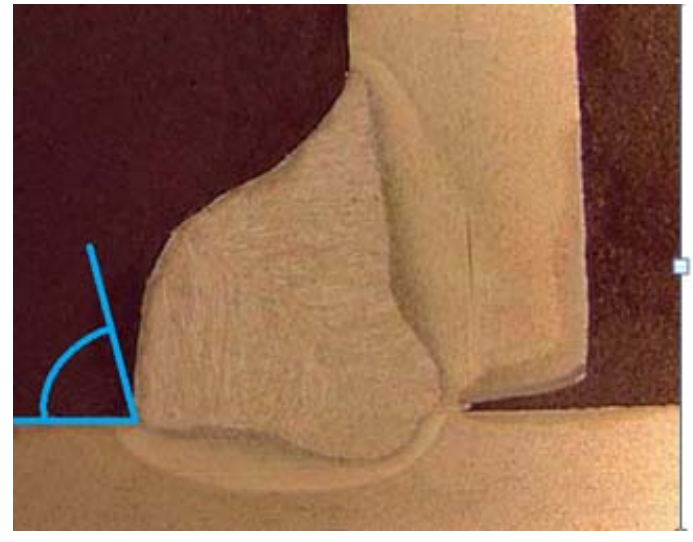

(a)

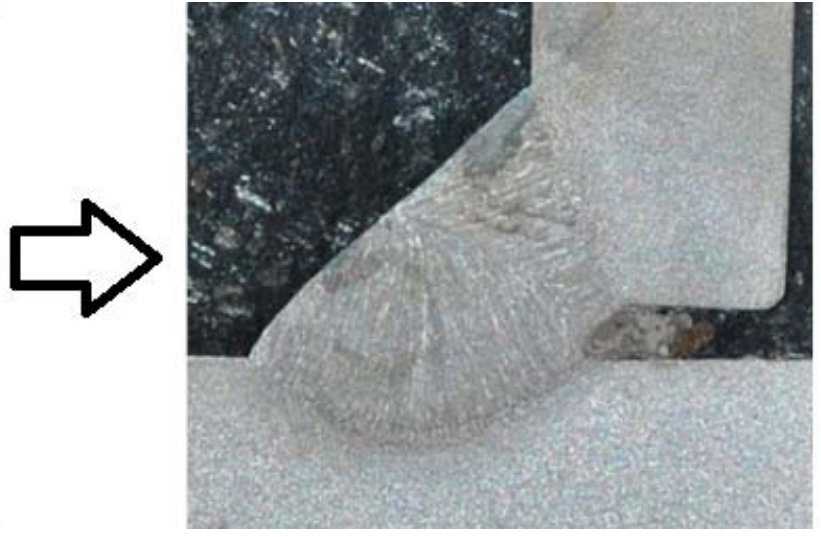

(b)

Figure 16 Cross section comparison (left: no gap, right: 1.5 mm gap)

Figure 16 shows the comparison on cross-section without and with the $1.5 \mathrm{~mm}$ gap using the same welding parameters. The improvement on the shape, especially the reentrant angle, is apparent. The use of a gap between the tee and the panel thus provides an effective way to reduce the penetration capability required to produce desirable weld beads. The heat input reduction capability of the DS-SAW can thus be effectively utilized to produce desirable fillet welds with minimized heat input. $1.5 \mathrm{~mm}$ is recommended for fillet welding on $3 / 16$ " thick plates. Compared with the conventional SAW, approximately $30 \%$ heat input reduction has been achieved. 


\section{Other Variants of DE-GMAW and Double-electrode Arc Welding}

A few variants have been proposed to extend the DE-GMAW concept or beyond the exact definition of DE-GMAW. The indirect arc method [36] has been independently proposed and developed at Shandong University, which establishes an arc between two consumable rods without the work-piece to be a part of the arc, either anode or cathode, will not be discussed below. It reduces the heat input to a minimum and shares a certain similarity with DE-DMAW but lacks the mechanism to adjust the heat input as the DE-GMAW and its variants do.

\subsection{Dual-Bypass GMAW}

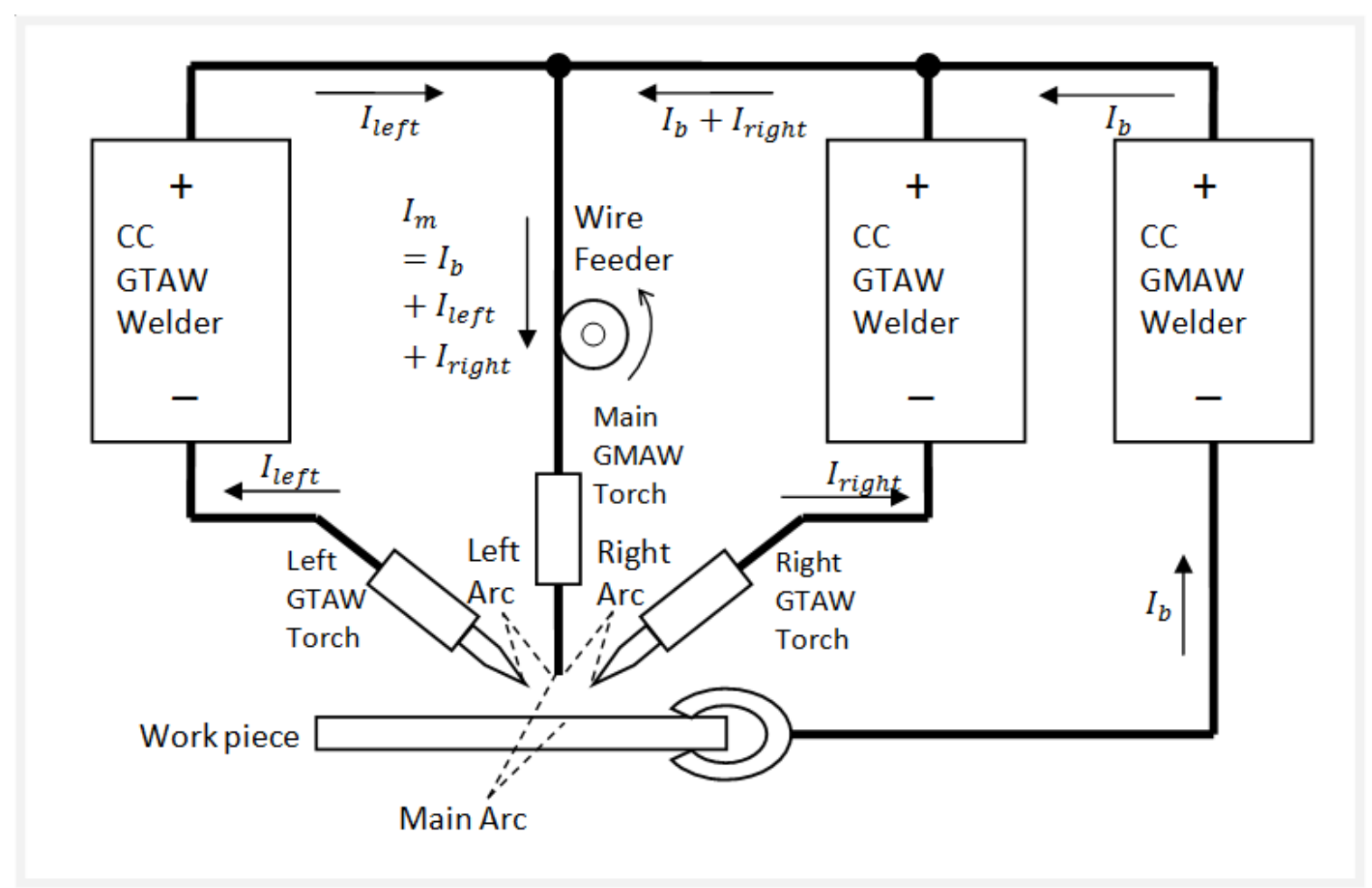

Figure 17 Principle of DB-GMAW

Dual-bypass GMAW process (DB-GMAW) is a variant of DE-GMAW [37-40] which, as can be seen from Figure 17, is established from a conventional GMAW system by adding two GTAW torches to provide two bypass loops for the melting current. The main loop is the path that the base metal current $\left(I_{b}\right)$ flows through, and the two bypass loops are the paths that the two bypass current $\left(I_{\text {right }}\right.$ and $\left.I_{\text {left }}\right)$ flow through. As illustrated in Figure 17 , the positive terminals of the three power supplies are connected together as a common positive terminal, and all of them are working in CC mode although CV may also be 
possible. The main torch is connected to the common positive terminal. The work-piece (or base metal) is connected with the negative terminal of the GMAW power supply. Each bypass GTAW torch is connected separately to the negative terminal of its corresponding GTAW power source. After the main arc is established between the tip of the electrode of the main GMAW torch and the surface of the work-piece, each bypass arc is established separately between the tip of the main electrode wire and the tip of its corresponding bypass electrode. The base metal current flows from the main electrode wire to the work-piece. The melting current for the main wire equals the sum of the base metal current and the two bypass currents:

where,

$$
I_{m}=I_{b}+I_{\text {left }}+I_{\text {right }}
$$

$I_{m}$ is the total welding current;

$I_{b}$ is the base metal current that flows through the work-piece;

$I_{\text {left }}$ is the bypass current that flows through the left bypass torch;

$I_{\text {right }}$ is the bypass current that flows through the right bypass torch.

Similar to DE-GMAW, DB-GMAW is also able to reduce the heat input of the welding process without reducing the deposition speed. As a result, the heat affected zone (HAZ) and the distortion of the work-piece can be reduced without affecting the productivity. Compared to DE-GMAW, more power supplies must be provided and the configuration of the system is more complicated to a certain extent.

For the metal transfer in DB-GMAW, the following has been found:

- The electromagnetic forces generated by the two bypass arcs (left and right) enhance the shrinking of the droplet neck and increase the anode area on the bottom of the droplet. The resultant influence of the neck shrinkage and the anode enlargement increase the detaching forces of the droplet.

- By changing the arc size and plasma flow speed, the bypass arcs increase the aerodynamic drag force of the droplet. As a result, the detachment of the droplet from the electrode wire is accelerated.

\subsection{Arc Assisted Hot-Wire GTAW}

In conventional gas tungsten arc welding (GTAW), the process often requires adding filler metals to produce desired welds. Currently, there are two primary approaches for filling the wire: cold wire GTAW and hot wire GTAW. In the cold wire GTAW process [41], the filler wire is added directly into the weld pool as is. In order to melt the wire faster, in the hot wire GTAW [42] as shown in Figure 18, the filler wire is pre-heated by a resistive heat while it is being fed into the weld pool. This resistive heat is generated from a separate 
current (typically an alternating-current (AC)) supplied to the filler wire that flows from the wire directly into the weld pool. The current is properly adjusted so that ideally the temperature of the filler wire can reach its melting point as soon as it enters the weld pool.

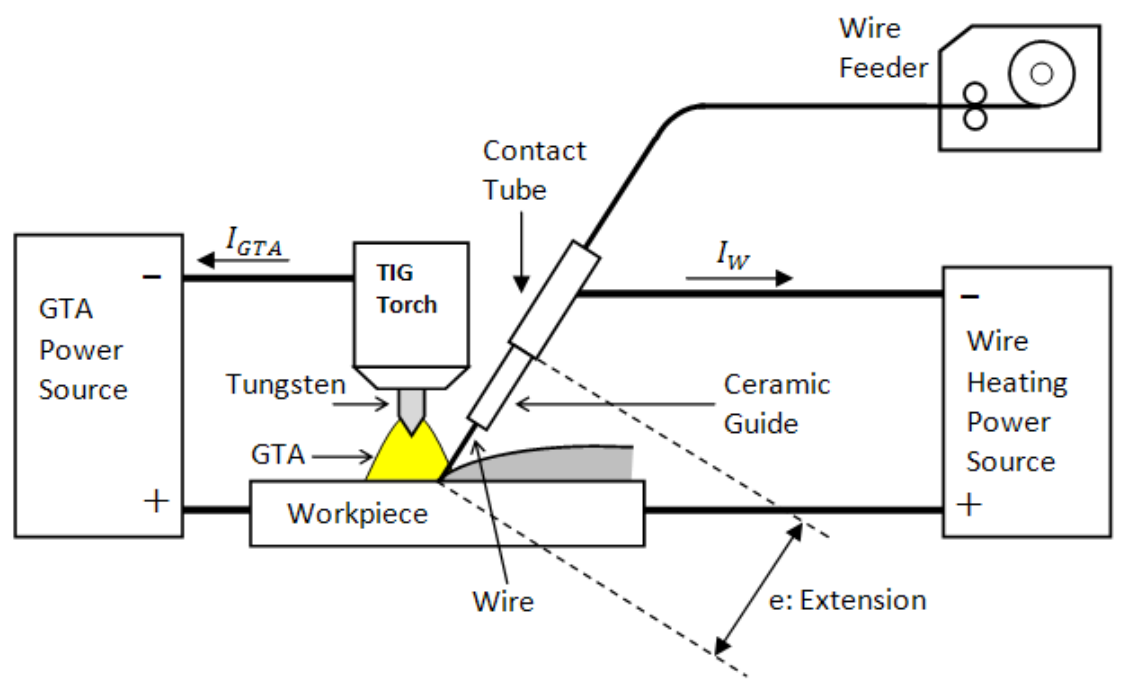

Figure 18 Principles of hot wire GTAW system [43]

However, even if hot wire GTAW is applied, its deposition speed is still limited especially when the electric resistivity of the wire material is relatively low. To resolve this issue, researchers at the Harbin Institute of Technology invented an Arc Assisted Hot Wire GTAW system. In this system, a second arc is added to increase the pre-heat temperature of the wire using the system as shown in Figure 19 [44, 45]. Although two arcs have been established on the surface of the filler wire in the arc assisted hot wire GTAW system, there is no arc between the two electrodes of GTAW torches. Therefore, the principle of the arc assisted hot wire GTAW is completely different from that of double-electrode based methods which are being discussed.

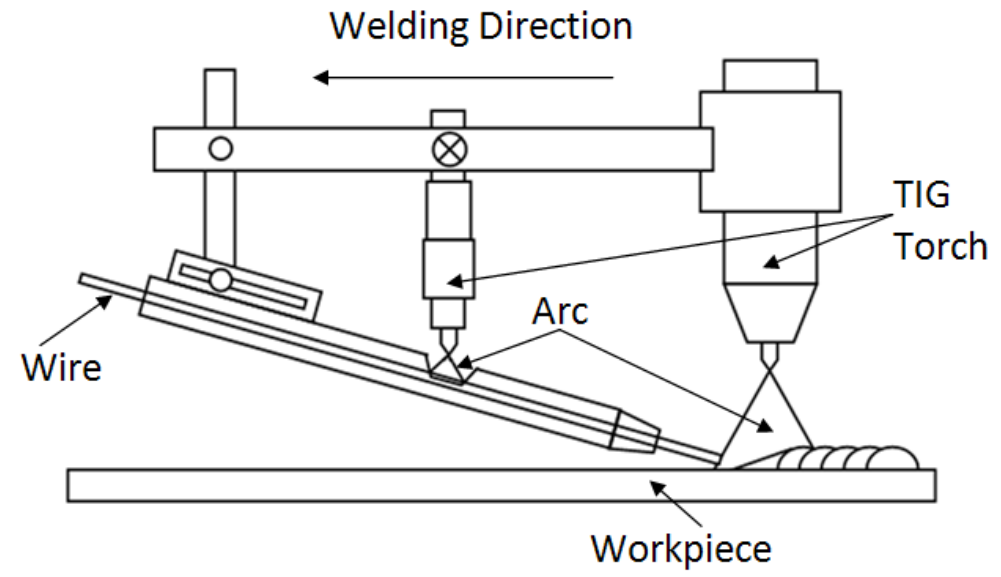

Figure 19 Arc assisted hot-wire GTAW [45] 


\subsection{Arcing-Wire GTAW [46] and Double-Electrode Arc Welding}

To increase the deposition speed without increasing the weld puddle and freely control the penetration and mass input in GTAW, the arcing-wire GTAW [46] as shown in Figure 20 has been developed at the Adaptive Intelligent Systems LLC [47] as a modification of GTAW by adding an arc (referred to as the side arc), established between the tungsten electrode and a filler, into the existing gas tungsten arc (GTA). It shares a similarity with the DE-GMAW in the sense that the current in the main electrode equals the base metal current and the current in an added electrode. However, the purpose is changed from melting the main electrode to melting the added electrode only and the main electrode is changed from consumable to non-consumable. For convenience, the authors propose the double-electrode arc welding (DE-AW) as a new category of arc welding processes which includes DE-GMAW, together with its variants, arcing-wire GTAW and other possible variants which use a main electrode to establish an arc with the work-piece and arcs with an added electrode or added electrode group.

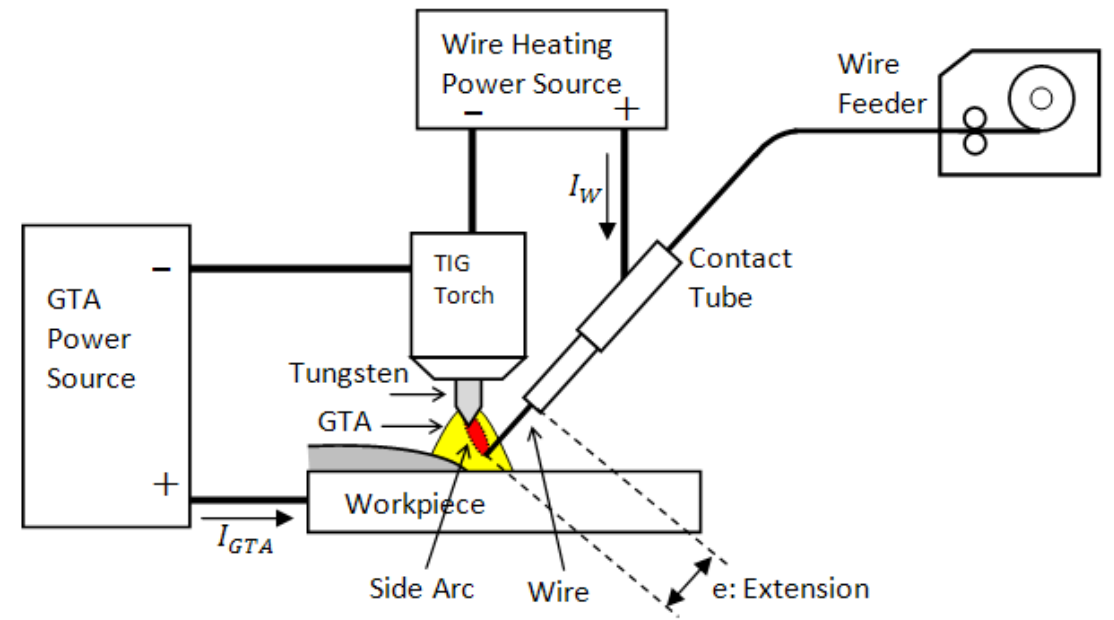

Figure 20 Principle of arcing-wire GTAW [46]

As shown in Figure 20, the arcing-wire GTAW system also needs two power sources. The GTA power supply is used to generate the GTA between the tungsten electrode and base metal; the wire heating power supply is used to generate the side arc between the tungsten electrode and filler wire. Because the negative terminals of the two power sources are connected together onto the tungsten electrode as a common point, a GTA current loop and wire heating current loop are both formed. The wire is melted not only by the resistance heat but also the side arc. The melting efficiency of the filler wire is thus much higher than that in the conventional hot wire GTAW especially for highly conductive filler such as copper and aluminum wires. Analysis suggests that the deposition speed achievable by and the wire melting mechanism for arcing-wire GTAW are similar with those for GMAW but the arcing-wire GTAW offers the arc controllability similar as conventional GTAW. 


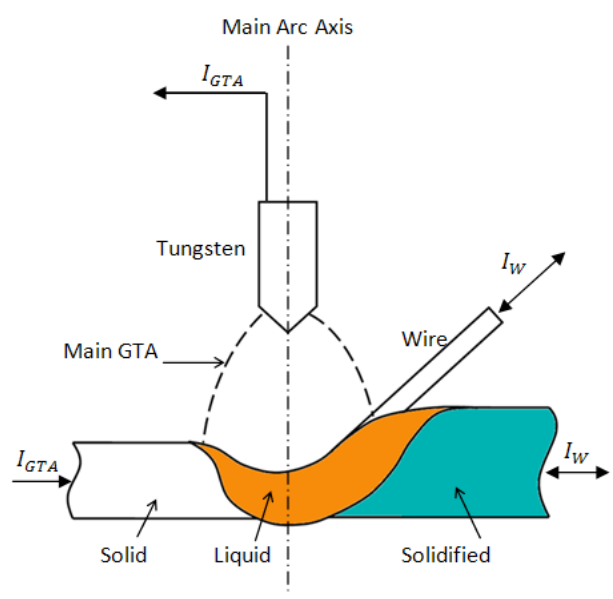

(a)

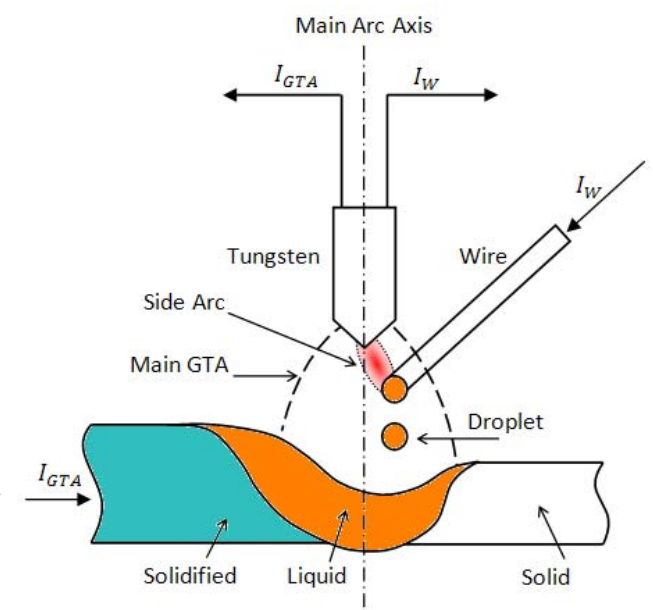

(b)

Figure 21 Comparison of hot wire GTAW with arcing-wire GTAW process

(a) Left: Arc and weld pool in hot wire GTAW;

(b) Right: Arcs and weld pool in arcing-wire GTAW

The primary difference between the hot-wire and arcing-wire GTAW lies in the melting mechanism for the filler wire. As can be seen in Figure 21(a), in the hot wire GTAW process, the filler wire is pre-heated at first by the resistance heat generated by the current flowing through the wire, and then melted within the weld pool by absorbing heat from the liquid metal in the weld pool. Similarly as in cold wire GTAW, the heat that finishes the melting of the filler wire is still the heat absorbed from the weld pool. There is thus no gap between the filler wire and the weld pool. However, in the arcing-wire GTAW process shown in Figure 21(b), the wire is actually completely melted by the side arc established between the tungsten and the wire before transferring into the weld pool. The wire can thus be melted similarly as in GMAW process at high speeds despite possible low resistivity of the wire. Further, this melting process does not depend on the weld puddle. The coupling between the deposition speed and arc energy is thus decoupled.

The Beijing University of Technology studied the metal transfer [47] on the arcing-wire GTAW and found that the metal melted from the filler may transfer into the weld pool in three modes: free transfer, touching transfer and bridging transfer. In free transfer, the metal detaches from the filler wire before it touches the weld pool. In touching transfer, the droplet of the melted metal starts to form with a gap to the weld pool surface and transfers into the weld pool after it touches the surface periodically. In bridging transfer, the wire enters the weld pool when it is still solid. The melting of the filler wire becomes similar as in the hot-wire GTAW with the resistive heat as the pre-heating source and the 
heat form liquid metal in the weld pool to finish the melting. The desirable free and touching transfer may be achieved from the given wire feed speed by adjusting the melting current and the wire position in relation to the tungsten appropriately [47].

\section{Summary and Future Work}

- Double-electrode GMAW changes the principle of conventional arc welding where the arc is established between the electrode and work-piece, and the electrode current equals the base metal current.

- Double-electrode GMAW reduces the base metal current from the main wire melting current by means of a bypass loop.

- Both non-consumable and consumable DE-GMAW, including their variants, increase and adjust/control the deposition efficiency from that of the conventional GMAW, resulting in a reduced and controllable heat input for the same deposition speed or an increased and controllable deposition speed for the same heat input.

- The currents in DE-GMAW and its variants can be controlled and the capabilities have been developed aiming at shipbuilding applications.

- DE-GMAW has been extended to a variety of double-electrode arc welding processes.

The future work should focus on the development of welding procedures for specific applications in order to transfer the DE-GMAW or DE-AW processes to the manufacturing industry and better modeling and understanding of the arc stability.

\section{Acknowledgement}

The Adaptive Intelligent Systems LLC thanks the support from the Navy under contracts N00024-09-C-4140, N65538-08-M-0049, and N65538-10-M-0110 and Kentucky Cabinet for Economic Development (CED) Office of Commercialization and Innovation through Kentucky Science and Engineering Corp. under agreements KSTC-184-512-08-038 and KSTC-184-512-09-067. The Adaptive Intelligent Systems LLC also thanks the approvals for public release from the Navy (5720/00DT 2013-0033, 5720/00DT 2012-0854, 5720/00DT 2011-0979). The University of Kentucky thanks the support from the National Science Foundation under grant CMMI-0355324. The authors also appreciate the technical assistance from Dr. Jeffrey D. Farren, Ms. Maria Posada, and Mr. Jonnie Deloach.

\section{Reference}

1. Ueyama, T., et al., Effects of torch configuration and welding current on weld bead formation in high speed tandem pulsed gas metal arc welding of steel sheets. Science and Technology of Welding and Joining, 2005. 10(6): p. 750-759. 
2. Tsushima, S. and M. Kitamura, Tandem electrode AC-MIG welding - development of AC-MIG welding process (report 4). Welding Research Abroad, 1996. 42(2): p. 26-32.

3. Talkington, J.E., Variable Polarity Gas Metal Arc Welding, in Welding Engineering 1998, Ohio State University: Columbus, Ohio.

4. Cary, H. and W. Chaisson, Variable Polarity Plasma Arc Welding, 1986, Metairie, LA, USA: Aluminum Assoc: Washington, DC, USA.

5. Ueyama, T., et al., AC pulsed GMAW improves sheet metal joining. Welding Journal (Miami, Fl), 2005. 84(2): p. 40-46.

6. Tong, H., et al., Quality and productivity improvement in aluminum alloy thin sheet welding using alternating current pulsed metal inert gas welding system. Science and Technology of Welding and Joining, 2001. 6(4): p. 203-208.

7. HARWIG, D.D., et al., Arc behavior and melting rate in the VP-GMAW process. Welding Journal, 2006. 85(3): p. 52S-62S.

8. HARWIG, D.D., Arc Behavior and Melting Rate in the VP-GMAW Process, 2003, Cranfield University.

9. Mahrle, A. and E. Beyer, Hybrid laser beam welding-classification, characteristics, and applications. Journal of Laser Applications 2006. 18(3): p. 169-180.

10. Liu, L., X. Hao, and G. Song, A new laser-arc hybrid welding technique based on energy conservation. Materials Transactions 2006. 47(6): p. 1611-1614.

11. Seyffarth, P. and I.V. Krivtsun, Laser-Arc Processes and Their Applications in Welding and Materials Treatment, 2002, Taylor \& Francis: New York.

12. Bagger, C. and F.O. Olsen, Review of laser hybrid welding. Journal of Laser Applications, 2005. 17(1): p. 1-14.

13. Steen, W.M. and M. Eboo, Arc augmented laser welding. Metal Construction, 1979. 11(7): p. 332-333.

14. Walduck, R.P. and J. Biffin, Plasma arc augmented laser welding. Welding and Metal Fabrication, 1994. 62(4): p. 3.

15. Reutzel, E.W., M.J. Sullivan, and D.A. Mikesic, Joining pipe with the hybrid laserGMAW process: Weld test results and cost analysis. Welding Journal (Miami, Fla), 2006. 85(6): p. 66-71.

16. Sullivan, M., Laser pipe welding project, in National Shipbuilding Research Program Welding Panel Meeting 2006: Provo, UT.

17. Zhang, Y.M., M. Jiang, and W. Lu, Double electrodes improve GMAW heat input control. Welding Journal (Miami, Fla), 2004. 83(11): p. 39-41.

18. Li, K.H., J.S. Chen, and Y.M. Zhang, Double-electrode GMAW process and control. Welding Journal (Miami, Fla), 2007. 86: p. 231s-237s.

19. Amin, M., Pulse Current Parameters for Arc Stability and Controlled Metal Transfer in Arc Welding. Metal Construction, 1983(15): p. 272-278.

20. Li, K.H. and Y.M. Zhang, Metal transfer in double-electrode gas metal arc welding. Journal of Manufacturing Science and Engineering, Transactions of the ASME, 2007. 129: p. 991-999.

21. Wu, C.S., et al., Numerical analysis of double-electrode gas metal arc welding process. Computational Materials Science, 2007. 39: p. 416-423.

22. Li, K.H. and C.S. Wu, Mechanism of metal transfer in DE-GMAW. Journal of Materials Science and Technology, 2009. 25: p. 415-418. 
23. Li, K.H. and Y.M. Zhang, Consumable double-electrode GMAW - Part 1: The process. Welding Journal (Miami, Fla), 2008. 87: p. 11s-17s.

24. Li, K.H. and Y.M. Zhang, Consumable double-electrode GMAW part II: Monitoring, modeling, and control. Welding Journal, 2008. 87: p. 44-s-50-s.

25. Li, K.H. and Y.M. Zhang, Interval model control of Consumable Double-Electrode Gas Metal Arc Welding process. IEEE Transactions on Automation Science and Engineering, 2010. 7: p. 826-839.

26. Waszink, J.H. and G.P.M.V.d. Heuvel, Heat generation and heat flow in the filler metal in GMAW welding. Welding Journal 1982. 61: p. 269s-282s.

27. Li, X.R., Y.M. Zhang, and L. Kvidahl, Penetration Depth Monitoring and Control in Submerged Arc Welding. Welding Journal, 2013. 92(2): p. 48s-56s.

28. Rawlings, J.B., Tutorial overview of model predictive control. Control System, IEEE, 2000. 20(3): p. 38-52.

29. Qin, S.J. and T.A. Badgwell, An overview of industrial model predictive control technology. Aiche Symposium Series, 1997(316): p. 232-256.

30. Morari, M. and J.H. Lee, Model predictive control: past, present and future. Computers \& Chemical Engineering, 1999. 23(4-5): p. 667-682.

31. Gupta, V.K. and R.S. Parmar, Fractional factorial technique to predict dimensions of the weld bead in automatic submerged arc welding. Journal of Institute of Engineering (India), Part ME 1989. 70(4): p. 67-75.

32. Chandel, R.S. and S. Bala, Relationship between submerged arc welding parameters and weld bead size. Schweissen Schneiden, 1998. 40(2): p. 28-31.

33. Chan, B., et al., Software system for anticipating the size and shape of submerged arc welds. Journal of Materials Processing Technology, 1994. 40(3-4): p. 249-262.

34. Tarng, Y.S., W.H. Yang, and S.C. Juang, The use of fuzzy logic in the Taguchi method for the optimisation of the submerged arc welding process. International Journal of Advanced Manufacturing Technology, 2000. 16: p. 688-694.

35. Tarng, Y.S., W.H. Yang, and S.C. Juang, The use of grey-based Taguchi methods to determine submerged arc welding process parameters in hardfacing. Journal of Materials Processing Technology, 2002. 128: p. 1-6.

36. Zhang, S.S., D.T. Wu, Z.D. Zou, S.Y. Qu, Effect of magnetic field on twin-wire indirect arc shape. Transactions of The Chian Welding Institute, 31(7): 87-90, 2010.

37. Liu, X., et al. Dual bypass GMAW of aluminum. in 35th North American Manufacturing Research Conference, NAMRC 35, May 22, 2007 - May 25, 2007. 2007. Ann Arbor, MI, United states: Society of Manufacturing Engineers.

38. Xue, C., et al., Edge extraction algorithm and analysis for dual bypass GMAW metal transfer. Shanghai Jiaotong Daxue Xuebao/Journal of Shanghai Jiaotong University, 2008. 42(SUPPL. 1): p. 90-92+96.

39. Xue, C., et al., Edge extraction algorithm for dual bypass GMAW weld pool. Shanghai Jiaotong Daxue Xuebao/Journal of Shanghai Jiaotong University, 2010. 44(SUPPL. 1): p. 4-7.

40. Xue, C., et al. High speed weld control system of dual-bypass MIG based on LabVIEW. in 2010 International Conference on Manufacturing Engineering and Automation, ICMEA2010, December 7, 2010 - December 9, 2010. 2010. Guangzhou, China: Trans Tech Publications. 
41. Meng, L., et al. Research and development of high energy pulse precision coldwelding technology. in 2011 International Conference on Advanced Engineering Materials and Technology, AEMT 2011, July 29, 2011 - July 31, 2011. 2011. Sanya, China: Trans Tech Publications.

42. Shinozaki, K., et al., Melting phenomenon during ultra-high-speed GTA welding method using pulse-heated hot-Wire. Yosetsu Gakkai Ronbunshu/Quarterly Journal of the Japan Welding Society, 2009. 27: p. 22s-26s.

43. Hori, K., et al., Development of hot wire TIG welding methods using pulsed current to heat filler wire - Research on pulse heated hot wire TIG welding processes (report 1). Yosetsu Gakkai Ronbunshu/Quarterly Journal of the Japan Welding Society, 2003. 21: p. 362-373.

44. Lv, S.X., et al., Arc heating hot wire assisted arc welding technique for low resistance welding wire. Science and Technology of Welding and Joining, 2007. 12(5): p. 431-435.

45. Lv, S.X., et al., Investigation on TIG cladding of copper alloy on steel plate. Science and Technology of Welding and Joining, 2008. 13(1): p. 10-16.

46. $\quad$ Chen, J.S., et al., Gas Tungsten Arc Welding Using an Arcing Wire. Welding Journal, 2012. 91: p. 9.

47. Chen, S.J., et al., Droplet Transfer in Arcing-Wire GTAW. Accepted for Publication in 7th Asia Pacific IIW International Congress 2013 July 8-10: Singapore. 